ACCELERATION AND COMMUNITY COLLEGE ENGLISH:

COMMUNITY OF PRACTICE, EQUITY, AND INSTITUTIONAL CHANGE

\author{
A5 A dissertation submitted to the faculty of \\ San Francisco State University \\ In partial fulfillment of \\ The Requirements for \\ EDD \\ .688 \\ The Degree \\ Doctor of Education \\ In \\ Educational Leadership
}

by

Mary Kathleen Barkley Gutierrez

San Francisco, California

August 2018 
Copyright by

Mary Kathleen Barkley Gutierrez

2018 


\section{CERTIFICATION OF APPROVAL}

I certify that I have read Acceleration and Community College English: Community of Practice, Equity, and Institutional Change by Mary Kathleen Barkley Gutierrez, and that in my opinion this work meets the criteria for approving a dissertation submitted in partial fulfillment of the requirements for the degree: Doctor of Education in Educational Leadership at San Francisco State University.

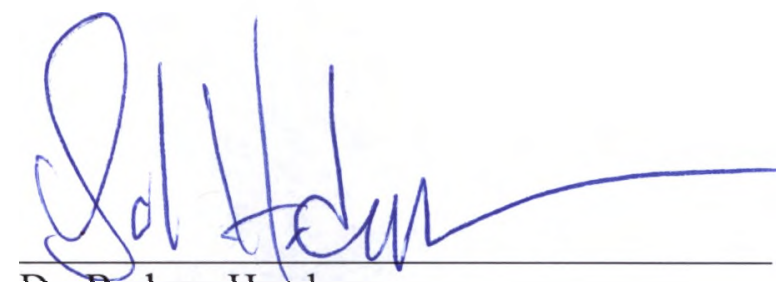

Dr. Barbara Henderson

Interim Program Director, Educational Leadership

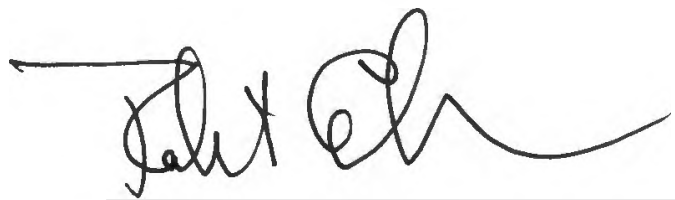

Dr. Robert Gabriner

Past Program Director, Educational Leadership

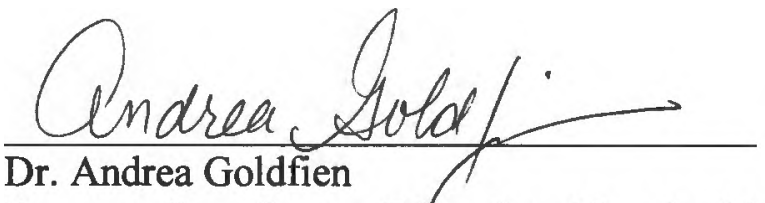

Program Coordinator, Educational Leadership 


\title{
ACCELERATION AND COMMUNITY COLLEGE ENGLISH: COMMUNITY OF PRACTICE, EQUITY, AND INSTITUTIONAL CHANGE
}

\author{
Mary Kathleen Barkley Gutierrez \\ San Francisco State University
}

2018

This study sought to determine the impact of structural reform in the developmental English sequence at a California community college. This multiple methods case study examined changes in student success and in faculty pedagogy. Analysis was framed by three research questions: 1 . How do structural changes affect rates of student success in a reform of an English developmental course sequence? 2. What challenges do faculty of college-level English face as a result of structural changes in developmental education? 3. How does participation in a community of practice impact faculty responses to structural changes in developmental English? The study used a convergent multiple methods design with quantitative data addressing student demographics, enrollment, and course grades. The qualitative data were drawn from program documents and transcripts from a focus group and interviews conducted with program faculty. Findings revealed that the reform increases equity in rates of student success. The range of preparedness among students presented challenges for faculty, which were partially addressed by increased course contact time. Further, a community of practice provided faculty with opportunities share instructional resources, gain validation, and practice intentionality. These produced the paradigm shift necessary to implement the structural change to the developmental English sequence Study implications inform the development and adoption of reformed models of developmental English at community colleges throughout California and the US.

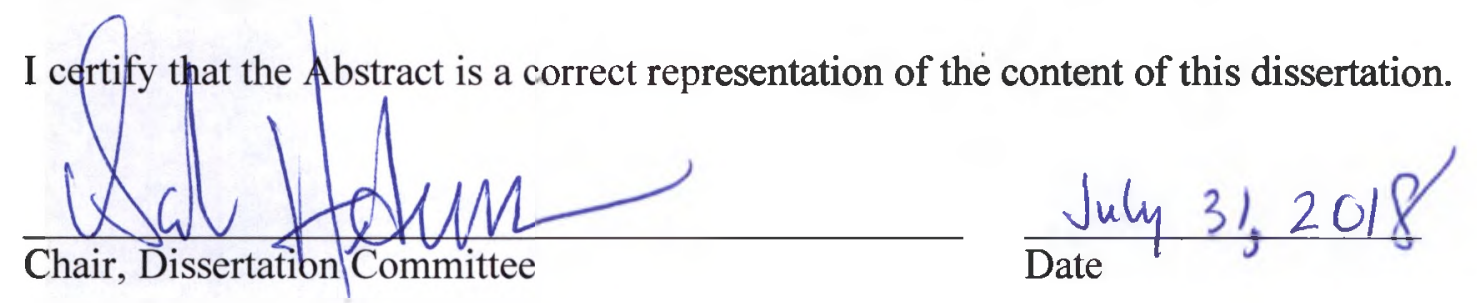




\section{ACKNOWLEDGEMENTS}

Thank you to my chair, Dr. Barbara Henderson, and my committee, Dr. Robert Gabriner and Dr. Andrea Goldfien, for their commitment to my success from the moment that I began the program. I appreciate their creativity, problem solving, and quest to serve all students. Thank you to Dr. Stan Pogrow for reading, responding, and encouraging. Thank you to my family, and especially my parents for their unwavering belief in me. My father's enthusiasm for this research makes me especially proud to have completed my doctorate. Years of "not yet" were finally realized in this work. I am grateful to have the love and patience of my husband and thought partner. My findings are better because I have him as a colleague. I am grateful to Regina Stanback Stroud who got me to the starting line, and Susan Lamb who saw me across the finish line. Finally, this study would not have been possible without the English and ESOL faculty at Cloudline

College. Daily they demonstrate commitment through their equity work that shows up as love, mentoring, many office hours, and a steadfast belief in students. I am immensely thankful for the leadership and friendship of Chris Gibson and our English 105 colleagues who conducted the work that I write about here. And thank you to our students. It is our great responsibility and reward to enter into the sanctuary of the classroom to engage with you every day. 


\section{TABLE OF CONTENTS}

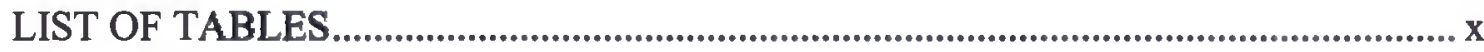

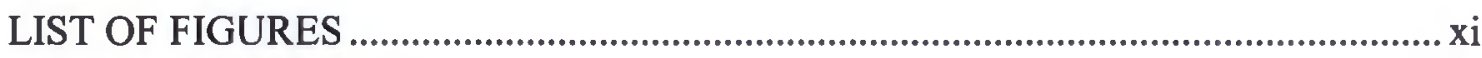

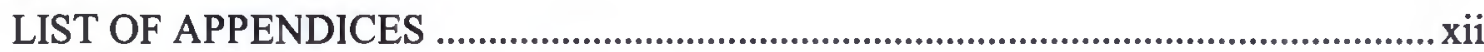

Chapter One: Purpose of the Study ................................................................................... 1

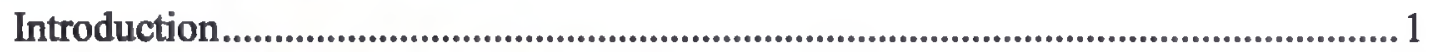

Assessment testing and remediation ..................................................................... 1

Remedial placement and inequitable outcomes...................................................2

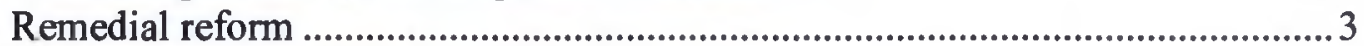

Problem Statement and Research Questions.............................................................4

Cloudline College English Sequence.........................................................................6

Quantitative Research .............................................................................................6

Qualitative Research ............................................................................................8

Theoretical Framework ................................................................................. 10

Ethical Considerations ....................................................................................13

Justification and Significance .................................................................................. 14

Chapter Two: Literature Review ..................................................................................... 16

Search Methodology ..................................................................................................... 17

The Efficacy of Traditional Developmental Education .............................................18

Equity and Developmental Education ........................................................................221

Structural Reforms of Developmental Education ......................................................22

Short developmental sequences. .....................................................................23

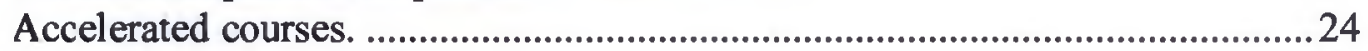

Accelerated Learning Program. .......................................................................22

National Replications of ALP............................................................................28

ALP Implementation Fidelity. ..........................................................................2 28

ALP Replication Outcomes. .............................................................................229

Tennessee statewide ALP adoption. ................................................................30

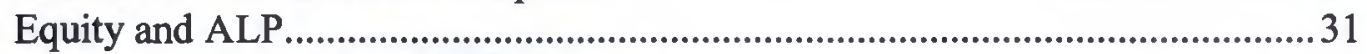

Critiques of Developmental Reform............................................................31

Florida developmental policy. ....................................................................................33

Curriculum and Pedagogy Reform ..........................................................................35

Gaps in the Research......................................................................................................36

Chapter Three: Methodology.............................................................................................. 38 


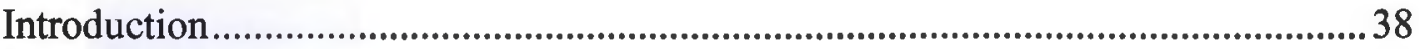

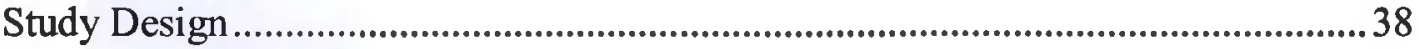

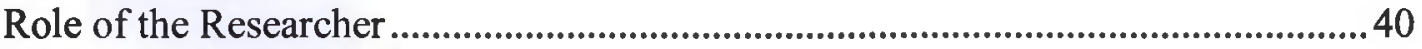

Research Questions and Sub-Questions................................................................ 42

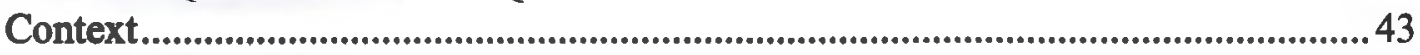

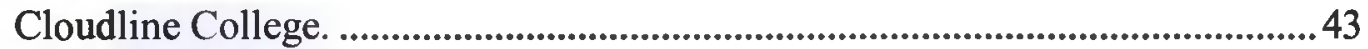

Student Population.................................................................................................... 44

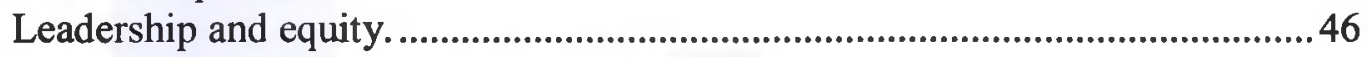

English department and equity leadership ....................................................... 46

Open source textbook. ....................................................................................... 47

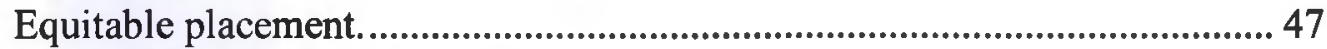

Collaboration with ESL faculty. .................................................................48

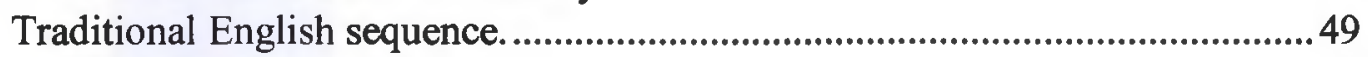

English 846 enrollment. ................................................................................... 50

Reformed English sequence.........................................................................5

California Acceleration Project................................................................................... 52

Cloudline College's community of practice. ................................................... 52

Student Participant Selection.................................................................................. 53

Quantitative Data Collection.................................................................................................55

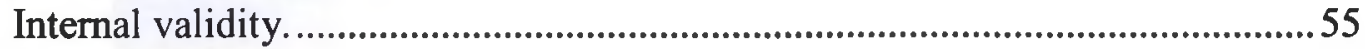

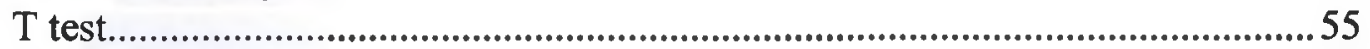

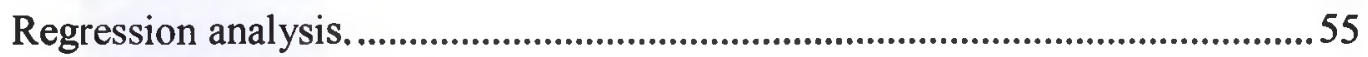

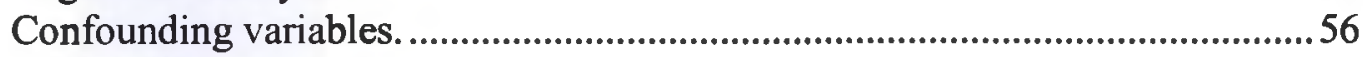

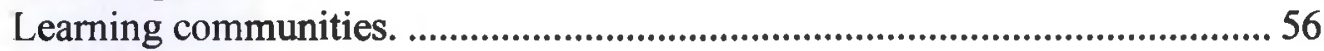

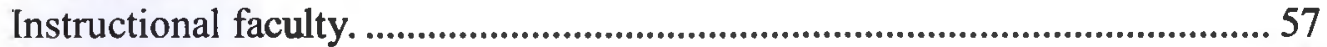

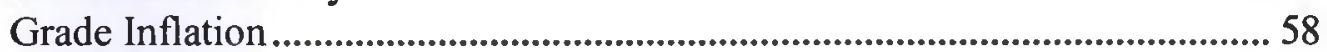

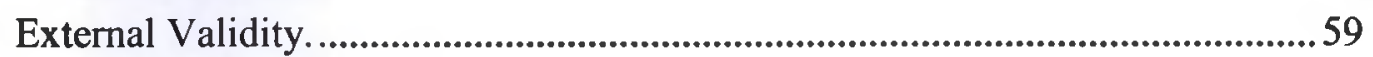

Faculty Participant Selection .....................................................................................59

Ethics and Protection of Human Subjects.................................................................... 60

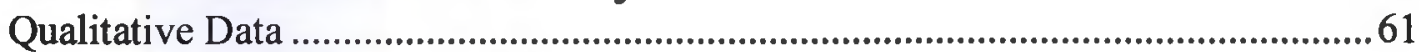

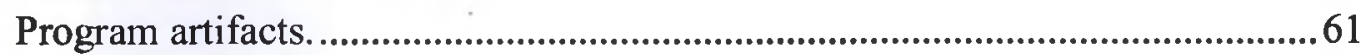

Focus group .........................................................................................................6 61

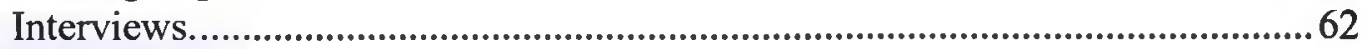

Sample and coding..........................................................................................62

Chapter Four: Quantitative Findings Regarding Student Outcomes ................................. 64

Success in the First English Course .........................................................................65

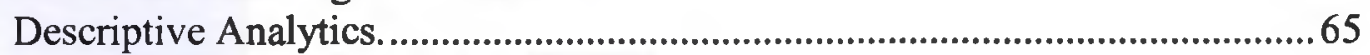

Welsh $t$ test of the first English course. .............................................................66

Success in the First College-level English Course ........................................................6

Welsh $t$ test of the first college-level course....................................................... 70 
Success in the College-level English Sequence............................................................. 71

Welsh $t$ test of the English sequence....................................................................72

Time to Complete the English Sequence .................................................................... 73

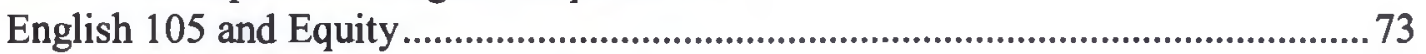

Student success disaggregated. .............................................................................. 74

Learning communities. ..................................................................................... 75

Welsh $t$ test and equity in English 105 vs English 846......................................76

Conditional inference tree definition. ............................................................... 78

Conditional inference test results............................................................. 78

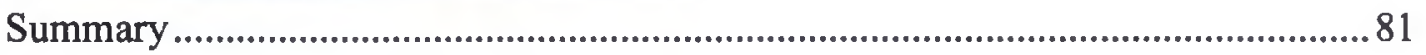

Chapter 5: Qualitative Findings....................................................................................... 82

Challenges of Implementing Structural Change ...........................................................8 83

A heterogeneous group of students..................................................................... 83

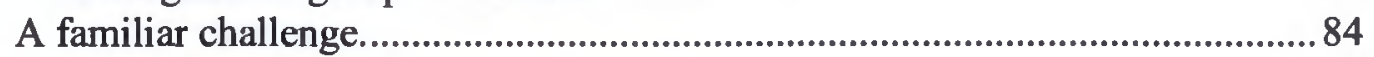

The real challenge: time........................................................................................... 85

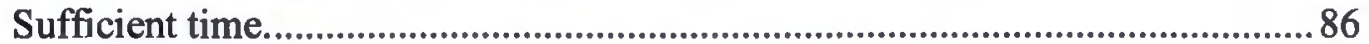

Summary on the challenges of implementing structural change .................................8 87

Faculty Outcomes from Participation in Community of Practice............................. 88

Inherited pedagogy and policies. ......................................................................89

Instructional isolation.............................................................................................99

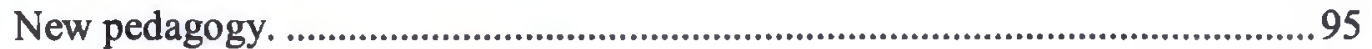

Faculty practiced growth mindset.......................................................................99

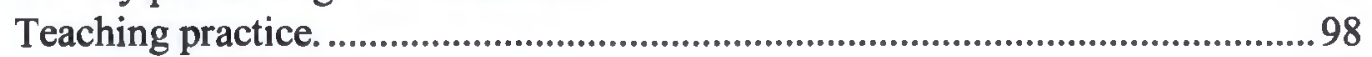

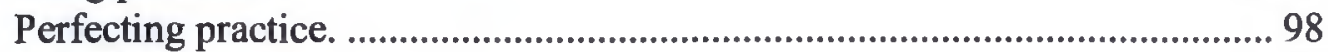

Adapting practice.

Transforming practice............................................................................. 100

Transforming themselves.................................................................... 102

Intentionality. I................................................................................................. 103

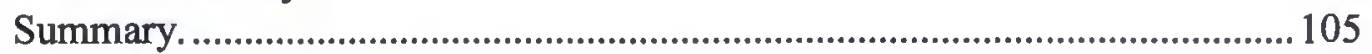

Chapter Six: Implications and Recommendations.................................................. 107

Reflections on Leadership and Change................................................................ 108

Reflections on Equity..........................................................................................111

The paradigm shift we need........................................................................112

Recommendations.........................................................................................113

Dismantling developmental sequences. ............................................................... 114

Instructional time. ................................................................................................ 115

Curriculum redesign......................................................................................116

Professional development. ....................................................................116

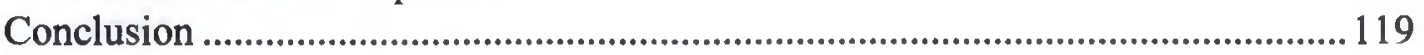




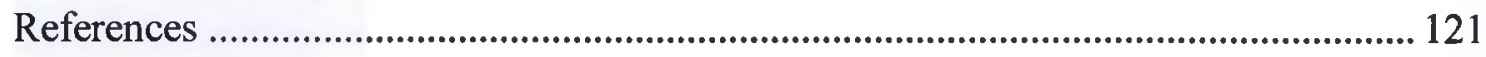

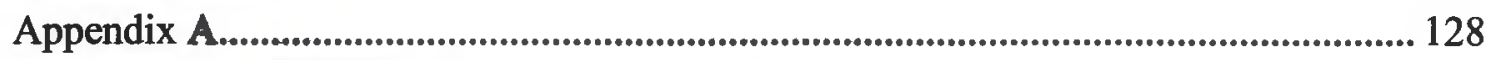

Interview with Katie Hern, June 11, 2018 ........................................................ 128 


\section{LIST OF TABLES}

Table

Page

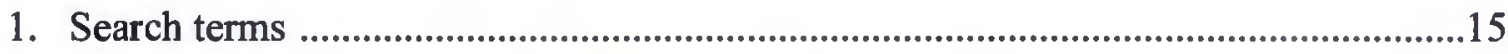

2. Cloudline College Student enrollment status .........................................................42

3. Cloudline College student racial and ethnic demographics .....................................43

4. Cloudline College student age demographics ......................................................44

5. Cloudline College student gender demographics .................................................45

6. Cloudline College traditional English sequence ...................................................49

7. Equity and access to college-level English ....................................................50

8. Reformed Cloudline College English sequence ..................................................51

9. Success in first English class .........................................................................65

10. Average means and sample size in first English class .......................................65

11. English $105 \mathrm{vs} 100 \mathrm{t}$ test ....................................................................66

12. English 105 vs $846 \mathrm{t}$ test ........................................................................67

13. College English enrollment patterns of 846 students (unduplicated) ........................68

14. Success in the first college-level course ...........................................................69

15. Success in the first college-level course $t$ test .................................................... 70

16. Success in the English sequence ............................................................ 71

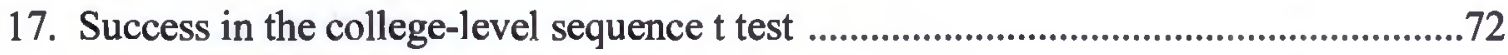

18. Success in English sequence ..................................................................... 73

19. Student success in English 846 and 105 disaggregated by race .............................74

20. Student success in English 100 and 105 disaggregated by race ............................76

21. African American, Latinx, and Filipin@ success in English courses t test ...............78 


\section{LIST OF FIGURES}

Figure

1. Conditional reference test first college-level course ..
Page

. .79 


\section{LIST OF APPENDICES}

$\begin{array}{lll}\text { Appendix } & \text { Page }\end{array}$

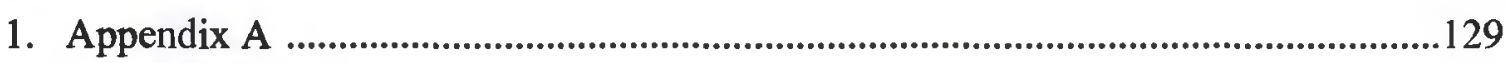

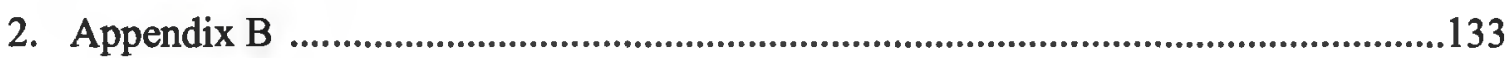




\section{Chapter One: Purpose of the Study}

\section{Introduction}

In September 2017, members of the California State Assembly and Senate demonstrated their concern about students' lack of access and progress to college-level courses in California community colleges by unanimously passing Assembly Bill 705. The bill reflects public awareness that too many students are placed into remedial college courses, and is informed by research which has shown that the more developmental classes a student is required to take, the less likely the student is to progress to a collegelevel course in the same discipline (Bailey, Jaggars, \& Jenkins, D., 2015). In fact, the majority of students who begin in developmental courses never enroll in a college-level course in that discipline (Hern \& Snell, 2014). Some researchers conclude that rather than fulfilling their intended purpose of preparing students for college-level work, traditional forms of developmental English education create barriers to college-level courses (Bailey, 2009; Bailey et al., 2015). Signed into law on October 13, 2017, Assembly Bill 705 mandates that placement be informed by high school transcripts for entering community college students, effectively reducing barriers to college-level courses and increasing equitable placement into college-level English and math.

\section{Assessment testing and remediation}

For decades, California legislators and community college officials have been aware that colleges' use of assessment tests for placement bars some college-ready 
students from college-level courses and instead forces them into remediation. The Seymour-Campbell Matriculation Act of 1986 stipulated that assessment tests "be used as an advisory tool only" but resulted in no change to the practice of using these tests for mandatory placement. In an effort to force compliance with the act, in 1988 the Mexican American Legal Defense and Education Fund (MALDEF) brought a lawsuit on behalf of student plaintiffs against Fullerton College and the California Community Colleges (CCC) chancellor. The suit provided evidence that Fullerton's use of assessment tests resulted in discrimination against students who were denied equitable access to collegelevel classes and transfer opportunities. The MALDEF suit intended to force compliance with the 1986 Seymour-Campbell Matriculation Act. Instead, when the suit was settled in 1991, it resulted in new Title 5 regulations but no change in practice. The MALDEF victory was a victory in rule rather than effect.

\section{Remedial placement and inequitable outcomes}

In 2016, twenty-five years after MALDEF's settlement, assessment tests were still being used as the sole placement tool in California community colleges. Seventy-five percent of all California community college students, and the great majority of AfricanAmerican, Latinx, and Filipin@ community college students begin college in remedial courses, courses that have a lack of documented success in preparing students to advance to college-level curriculum. The California Community College's Student Success Scorecard shows that of all students who enrolled in one or more remedial English 
classes, $45 \%$ complete a college-level English course within a six-year period, including 42.6\% of Latinx students and $29.6 \%$ of African American students. Like assessment tests, remedial English in California community colleges plays a role in limiting the number and diversity of community college graduates, particularly Latinx and African American students who are over-represented in developmental classes.

\section{Remedial reform}

Reforms of remedial education have increased the likelihood that students who are gaining equitable access to college-level English and math courses will be successful in these courses (Bailey, Jeong, \& Cho, 2010; Coleman, 2014; Hern, 2012). The California Acceleration Project (CAP) leads the effort to reform California community college developmental education and promotes a model of developmental English adapted from the Community College of Baltimore County's Accelerated Learning Program (ALP). In the Baltimore model, students who place in developmental English are given the option to take a college-level English course supplemented by a co-requisite course rather than completing the traditional developmental course. The co-requisite course provides students with additional time and support for reading and writing skill development (Jenkins, Speroni, Belfield, Jaggars, \& Edgecombe, 2010). The ALP model has been adopted in Tennessee, Arkansas, Indiana, Michigan, Virginia, Colorado, and West Virginia, (Coleman, 2014) and is being adopted and modified in California. According to the California Acceleration Project, twenty California community colleges 
are in the process of implementing the ALP model, including Cloudline College, a pseudonym for a college in northern California which is piloting English 105, the focus of this research.

Whereas the Community College of Baltimore County's (CCBC) implementation of ALP has been researched (Cho, Kopko, Jenkins, \& Jaggars, 2012). Coleman (2014) argues that further research on ALP implementations and modifications is needed, stating that the colleges that implement ALP "often have very different environments from that at $\mathrm{CCBC}$, and there is a dearth of information of how these colleges fare when they do implement the model" (p. 2). In this dissertation, I will research the impact of Cloudline College's implementation of English 105, a modified ALP model, on teaching and student success.

\section{Problem Statement and Research Questions}

In 2012 , close to $60 \%$ of all first-time Cloudline College students began their college English sequence with English 846, a developmental course one level below the college-level sequence, English 100 and English 110. In a six-year period, only 57\% of these students, disproportionately Filipin@ and Latinx, completed English 100. In Fall 2016, Cloudline College implemented a structural reform of developmental education by changing placement standards and mechanisms, effectively reclassifying students.

Students who before had been designated developmental were classified as college-level under the new placement process. To accommodate many students at the college level 
who previously would have placed into English 846, faculty developed a new collegelevel course, English 105. This course develops the same student learning outcomes as English 100, but allows faculty 2 units of additional time to enhance scaffolding and provide other support. This study seeks to determine the impact structural reform of developmental English has on student success and faculty teaching. As such, my research is guided by three questions:

1. What challenges do faculty of college-level English face as a result of structural changes in developmental English?

2. How does participation in a community of practice impact faculty responses to structural changes in developmental English?

3. How do structural changes affect rates of student success in a reform of English developmental course sequence? The results of this research will add to the number of documented and researched implementations of ALP at institutions other than County of Baltimore Community College. Furthermore, as California community colleges implement AB 705 and use high school transcripts for placement, they are likely to experience an increase of students beginning in college level courses. Co-requisite models have potential to help colleges maintain or increase levels of student success even as students who were previously classified as developmental begin in college-level courses. 


\section{Cloudline College English Sequence}

With nearly $60 \%$ of all first time Cloudline College students beginning their college English sequence with English 846, a developmental course one level below the college-level sequence, English faculty decided to increase access to college-level courses. In Spring 2016, the scores required for placement in college-level English were reduced slightly and placement by high school transcript replaced assessment testing as the preferred method of placement. Consequently, in Fall 2016, the majority of first time Cloudline College students began their college English sequence with English 105, and satisfied their college English requirements by successfully completing English 105 and English 110. With this change, English 846 was no longer a default placement for Cloudline College students, and is implemented specifically for students who need and request the opportunity to learn English at a slower pace. This dissertation studies the impact of this structural change to the developmental English sequence.

\section{Quantitative Research}

To understand how structural changes in developmental English affect rates of student success, I analyzed raw data from English enrollments in English 846, English 105, English 100 and English 110 from Fall 2012 through Fall 2017. Data for English 105 was available from the initial pilot in Fall 2015 though Fall 2017, the termination of all data collection for this research. I measured student success within English 105, defined as passing the course with an A, B, or C. Additionally, I determined the rate at 
which students who began in English 105 successfully completed English 110 with an A, $\mathrm{B}$, or $\mathrm{C}$ and the time to successful completion of the full English sequence. Data was disaggregated by race and gender.

My analysis produced the same three measurements - initial course success, success in English 110, and time for sequence completion - for students starting in English 105 and two other starting points in the English sequence, English 846 and English 100. I compared data from English 105 with data from English 846, the traditional developmental starting point, and English 100, the traditional college-level starting point. Comparing English 105 data to English 846 data demonstrated any changes in the course success and sequence completion for students who would have been classified as developmental students. Comparing English 105 data to English 100 data provided a different point of comparison. As the traditional first college-level course, English 100 provided a point of comparison for college-level rates of success.

In addition to an analysis and comparison of aggregated English 105, 846 and 100 data, disaggregated data provided the basis for an analysis of English 105's impact on groups and equity gaps. Changes in placement and English 105 were intended to produce equitable outcomes in college-level English. Disaggregated outcome data determined if English 105's intended benefits were realized. 


\section{Qualitative Research}

English 105 implemented a significant structural change to developmental and college-level English, ending developmental placement for nearly all entering students. Faculty were accustomed to teaching most developmental students eleven units over three semesters. English 105 resulted in faculty teaching many students for eight units over two semesters. My research documented and analyzed what faculty found challenging as they transitioned to fewer semesters and units with their students. I also researched how participation in the English 105 community of practice impacted faculty responses to this significant structural change.

Faculty teaching English 105 participated in a community of practice that was designed to help them adjust to the developmental reform and structural change. Faculty applied to participate in the community of practice. Their participation was voluntary, although faculty were required to participate if they wanted to teach English 105 . Faculty who participated in the community of practice had the advantage of being eligible to teach in programs like learning communities which relied on English 105. Of 44 English faculty members, 38 have participated in the community of practice since English 105 transitioned from a pilot in Fall 2015 and Spring 2016 to a full scale implementation in Fall 2016. Three community of practice cohorts, Fall 2016, Spring 2017, and Fall 2017, provided the basis for my research in this dissertation. 
The English 105 community of practice was developed and implemented by English 105 faculty. An English faculty member with extensive leadership experience with the California Acceleration Project volunteered to lead development of a curriculum model for English 105 and to facilitate the communities of practice. While the first community of practice was facilitated by this faculty coordinator alone, a volunteer from the first cohort joined in the facilitation of the second cohort. Likewise, a volunteer from the second cohort joined the pair to lead the third cohort. Faculty in the community of practice were also called on to lead workshops or activities that draw on their instructional strengths.

An asset-based model of professional development, the community of practice utilized the strengths and assets of the department to enlarge knowledge, skills, and resources for the effective teaching of English 105. As such, every participant contributed to the department's growing understanding of effective teaching. Throughout their participation in the community of practice, faculty contributed meeting notes, letters to future 105 teachers, reflections, syllabi, assignments and other documents to the program's bank of artifacts. I drew on these artifacts for my research. In addition, I conducted interviews with members of the first cohort, a focus group with the second cohort, and follow-up interviews with three members of the second cohort. I conducted my analysis of artifacts, interviews, and focus groups using an approach to grounded theory described by Charmaz (2006). I developed initial codes and then identified 
themes in order to describe and analyze the impact of the community of practice on faculty teaching.

\section{Theoretical Framework}

Community of practice provides the framework to support structural change and promote transformation. Community of practice as a model for professional learning and development was identified by Lave \& Wenger (1991) in their observations of apprenticeship. Lave \& Wenger (1991) observed that professionals were drawn together to solve problems and learn because of their common interest and expertise in a domain or field. Communities of practice develop informally (McDermott \& Archibald, 2010) and intentionally (Wenger, 1998) as is the case in the California Acceleration Project, which conducts formal communities of practice to support the understanding and adoption of acceleration in California community colleges.

Research conducted about the California Acceleration Project has focused on its models for developmental reform and not CAP's model for professional development. Likewise my research is not about CAP's communities of practice, but draws on CAP's communities of practice as a framework for professional development. Without publications to consult on CAP's use of community of practice, I contacted and interviewed CAP founder and my community college colleague, Katie Hern. The full text of this interview is available in Appendix A. 
The California Acceleration Project adopted community of practice as its professional development model because $3 \mathrm{CSN}$, an early partner, was working with a theory of change that involved a peer-to-peer model of professional development. Community of practice provided a means to formalize the peer-to-peer relationship and maintain the non-hierarchal model that Katie Hern and CAP founders wanted (Hern interview, June 12, 2018).

Communities of practice are built around shared values and expertise. Founders of the California Acceleration Project welcomed faculty who could work with CAP principles and colleges who would commit to offering accelerated classes to join the acceleration project. The three CAP principles are supported by empirical evidence and provide a frame and a foundation for CAP's work. The principles maintain that students benefit from shorter developmental pathways and that colleges must reduce their reliance on standardized tests for placement. The third principle includes several best practices for developmental curricula including backwards design (Wiggins, McTighe, Frost, Kiernan \& Association for Supervision and Curriculum Development, 1998), just-in-time remediation (Novak, Patterson, Gavrin, \& Christian, 1999), collaboration, and intentional support for students' affective needs. Hern said that from the beginning the principles "united us, the framework, and the people who stepped forward were compelled by the framework and the agreements" (Hern interview, June 12, 2018). The principles positioned the CAP to achieve change within California Community Colleges. 
Community of practice, small groups of faculty working and learning together, was CAP's means of achieving the change.

Community of practice functioned effectively as a model for change and professional learning. In early planning, Hern envisioned that community of practice would provide faculty the opportunity to work through problems of practice with other faculty. She recalled that

Participants were there to grapple with the problems. Community of practice has a flattened hierarchy. We didn't have authority; we were just facilitators of a process. People were there with the intention of learning to do something different. At the time it seemed so radical to make the structural change. People were changing from three levels below transfer to one, or two levels below to one. We were there to say, 'here's what I use in my class.' They were hungry to see the approaches. (Hern interview, June 12, 2018)

Cloudline College adopted Community of practice as a result of our exposure to its use in the California Acceleration Project. Community of practice is well suited to the culture at Cloudline College, because of its reliance on faculty expertise. This assetbased approach to professional development recognizes faculty know-how (Hildreth, Kimble \& Wright, 2000), and reinforces the asset-based approach that English 105 faculty take with students when they regard students as having knowledge and skills that can be built upon during their time in English 105. 
Wenger, McDermott, \& Snyder (2002) illustrate that members of a community of practice can undergo change through the process of participation by deepening knowledge and expertise. Lave \& Wenger (1991) explains that community of practice makes other changes possible, "not simply changes of a quantitative sort" (81), but transformations of understanding that lead to transformations of identity. Transformation is also of interest to Kezar \& Gehrke (2017) who refer to communities of transformation, and study their role in "changing broader systemic and institutional norms (i). Deepening expertise, transforming identity, and transforming systems and norms are types of change that the community of practice framework supports and facilitates.

\section{Ethical Considerations}

I served as the Dean for Language Arts at Cloudline College. My leadership as dean meant that I worked to provide a supportive environment and creative space for faculty to transform education. In this role, I served as a thought partner in the development of English 105 and the community of practice. I supported faculty work to change placement standards and practices. Additionally, I ensured that faculty work was given every opportunity to be successful by advocating for acceleration and English 105 with administration, counseling, testing, and with colleagues across the district. Furthermore, as dean, I supported reassignment for the coordinator of English 105 and compensation for community of practice participants. I advocated for the inclusion of English 105 in learning communities, ensured that there were enough sections of the 
course to meet student need, and scheduled faculty to teach the course. I was committed to the success of the course as part of my responsibilities as dean.

Whereas there are important hands-on roles for deans, there are equally important hands-off roles. In terms of English 105, this meant that I discussed curriculum with faculty, but that curricular decisions are theirs. It also meant that the community of practice is space and time designed for and by faculty. My direct contact with the cohorts was minimal or non-existent. The community of practice is facilitated by faculty peers, who communicate with the cohort, collect artifacts (which could be submitted anonymously), facilitate meetings, and convened the focus group. As the researcher dean, my role is not to direct but to understand and document the impact of the community of practice on faculty and the impact of the course on student success.

\section{Justification and Significance}

California community colleges play a critical role in ensuring that African American, Latinx, and Filipin@ communities have access to high quality education and better opportunities for careers. The need for students from these communities to enroll in and successfully complete college-level English is hindered by traditional forms of remedial education and the deficit framework that may accompany remediation. However, accelerated courses and pedagogy have been shown to be effective in increasing enrollment in and successful completion of college-level English. The case 
study is an important first step in determining the impact of Cloudline College's English 105 model on equitable student success and developmental English reform.

As a study of a reform of developmental education, this research moves between paradigms, the traditional remedial paradigm which reproduced inequity and a reformed paradigm in which colleges assume responsibility for equitable outcomes. Both of these paradigms are reflected in the body of research on the efficacy of developmental education and models for its reform. The literature review demonstrates the need for information about how colleges implement reformed models. In order to provide robust information about Cloudline College's implantation of a modified co-requisite model, this research draws on two large quantitative and qualitative data sets. Five years of student records are analyzed in Chapter 4 to provide an understanding of equity and student success in college-level English and the English sequence. This quantitative analysis is followed by a qualitative study of the faculty experience implementing the corequisite model while participating in a community of practice. Together the quantitative and qualitative findings provide valuable information for colleges preparing to implement reforms of developmental English and/or address systematic inequity in developmental education. 


\section{Chapter Two: Literature Review}

Remedial education has as a core premise that all students attending college should be able to demonstrate a minimal level of proficiency, established as college-level, in reading comprehension, grammar and punctuation, and quantitative skills. This premise assumes that college level is not only clearly defined but that it also can be accurately assessed through standardized tests. In the traditional model, students deemed deficient receive instruction that decontextualizes language, isolates reading from writing, and attempts to teach students building blocks of language independently and incrementally. As instruction begins with the smallest unit, the sentence, and progresses to paragraphs in a subsequent semester (Scott-Clayton \& Rodriguez, 2012), it may take students three semesters to advance to a course on the simple, five paragraph essay.

Literature on remedial and traditional developmental English education and its reform frame this study. Following an examination of the efficacy and equity of traditional remedial structures, I address types of reforms of developmental education. Structural reforms eliminate requirements or condense courses. Acceleration is a reform model that moves students more quickly through curriculum. Some accelerated models move students through developmental curriculum at a rapid pace. Others bypass developmental curriculum, such as the co-requisite model which supplements collegelevel coursework with a co-requisite support class. 
Community College of Baltimore County's Accelerated Learning Program (ALP), first implemented in 2007, figures prominently in this literature review as it led to the dominant reform model of developmental English, the co-requisite model. The corequisite model suggests that many students who colleges classify as developmental can be successful at the college-level if they receive additional support in a supplemental, corequisite course. I conclude with a review of literature on the ALP, and on replications and adaptations of this model undertaken from 2010 through 2017.

\section{Search Methodology}

The literature in this review was collected through two means: searches of electronic databases and branching. I searched abstracts in ERIC, Education Database, Education Full Text, Education Research Complete, the terms shown in Table 2 below.

Table 2

Search terms

\begin{tabular}{|l|l|l|}
\hline Primary research term & AND & AND \\
\hline remedial, or & English, or & Higher education, or \\
\hline developmental, or & writing, or & community college, or \\
\hline Basic Skills, or & composition & two-year college, or \\
\hline Accelerated, or & & junior college \\
\hline Acceleration & & \\
\hline
\end{tabular}


This search yielded 1225 articles. I limited my searches to literature published in 2006 or since. I combed through the results of these searches selecting relevant empirical research published in English in peer reviewed journals, which reduced the articles to 362. I limited results to studies of higher education in the United States and filtered further by looking for research that has findings about developmental English in higher education.

Within these results, I filtered out articles that focused on the impact of developmental English on English language learners. Many of these students experience a compounded effect of two developmental systems, which is not the focus of this research. My focus on developmental efficacy and reform made it necessary to complement this literature with empirical reports and working papers. In addition to creating my own searches, I consulted the lists of references in the sources I selected for use. Finally, I searched Google to locate research or reports on co-requisite implementations that I was unable to locate via databases. This search process yielded more than fifty articles that I consulted for this literature review.

\section{The Efficacy of Traditional Developmental Education}

A growing body of work provides evidence that traditional developmental education does not successfully prepare and progress most students through college-level English sequences. (Bailey, 2009; Bailey et al., 2016; Bailey, Jaggars, Smith, \& ScottClayton, 2013; Clotfelter, Ladd, Muschkin, \& Vigdor, 2014; DeNicco, Harrington, \& 
Fogg, 2015; Scott-Clayton \& Rodriguez, 2012). Statewide studies from public four-year institutions in Ohio (Bettinger \& Long, 2009) and North Carolina community colleges (Clotfelter et al., 2014), found that being required to take a remedial course in a subject reduces the likelihood that the student will pass a college-level course in that same subject. Scott-Clayton \& Rodriguez (2012) and (Bailey, T. et al., 2015) concluded that developmental courses serve to divert students away from college-level coursework rather than to build skills for college. Not even half of community college students complete the developmental coursework to which they have been referred (Bailey, T. et al., 2015). In California, $60.4 \%$ of community college students who begin with developmental courses do not complete a certificate, degree or transfer in six years (Rodriguez, Olga, Mejia, Marisol Cuellar, \& Johnson, Hans, 2016).

The structure of traditional developmental sequences appears to contribute to students' lack of progress through course sequences. Traditionally, developmental coursework requires sequences of classes that can delay the start of college-level unit accumulation, potentially for multiple semesters. As shown in the City College of San Francisco 2018-19 college catalog, students may be required to take up to six developmental English courses prior to enrolling in their first college-level English course. (K. Hern \& Snell, 2010) argued that the high attrition rates in developmental sequences are attributable to the length of the sequences. They observe that "attrition is high in developmental sequences, but more important, attrition is exponential. As 
students fall away at each level, the pool of continuing students gets smaller and smaller until only a fraction of the original group remains to complete the sequence" (K. Hern, 2012). The time and finances required to complete long developmental sequences are discouraging to students. Likewise, the requirement to repeat high school course content frustrates students who are college-ready and often reinforces stereotypes that groups of students are not college material. As a result, students exit college prior to enrolling in the developmental sequence or decline to continue after successfully completing some developmental coursework (Bailey, 2009; Rodriguez, Olga et al., 2016).

Numerous students who are designated developmental demonstrate that they are college-ready. Bremer et al. (2013) and Cooper et al. (2017) provided evidence of college-readiness among developmental students who accumulate units in college courses other than English and/or math prior to completing developmental requirements. Of these students, some opt not to complete their developmental requirements, despite passing grades in lower developmental courses. Bremer et al. (2013) found that of students who enrolled in one or more developmental courses in the first term of college $(\mathrm{N}=7898), 72.6 \%$ enrolled in the second term, while only $44.5 \%$ enrolled in a third despite demonstrating college-readiness by having an average 2.53 GPA in nondevelopmental courses. A study of persistent, transfer-focused California community college students $(\mathrm{N}=875,630)$ found that $18 \%$ of these students (or 157,613$)$ had 
completed 60 or more transferable units with a 2.0 or higher but were missing required courses in math and/or English (Cooper, et al., 2017).

Not only are many students without developmental English college-ready, some are even graduation-ready. Cooper et al. (2017) found that transfer-ready community college students are held back from graduation due to developmental requirements. Of these students $64.6 \%$ (or 100,872) had completed all other graduation requirements but lacked the developmental and college-level English required for completion (Cooper et al., 2017). Whether the traditional developmental structure discourages students from initial enrollment or the developmental requirement itself keeps otherwise qualified students from completion, traditional developmental education appears to erect barriers rather than facilitating access to completed certificates and degrees--effectively undermining the open-access mission of California community colleges.

\section{Equity and Developmental Education}

Developmental education has a disproportional impact on students who are historically underrepresented in higher education. Students who are African American, Latinx, and low income are referred to developmental education at rates higher than their white and Asian counterparts (Attewell, Lavin, Domina, \& Levey, 2006; Bailey, 2009). Using NELS:88 data, Attewell et al. (2006) conclude that African American students are $11-16 \%$ more likely to enroll in developmental classes in all levels of higher education. In California, African American, Latinx, and Asian students are overrepresented in 
developmental English (Perry, Bahr, Rosin, \& Woodward, 2010)(Perry, Bahr, Rosin, \& Woodward, 2010). Students who attend community colleges are more likely to be referred to developmental classes (Attewell et al., 2006). When community college students are matched to sets of like peers who attend 4-year private institutions, they are $11 \%$ more likely to take developmental coursework and $7 \%$ more likely than the same student profile attending a four-year, public institution.

The impact of developmental education on historically underrepresented populations is compounded by the increased likelihood of underrepresented students attending community college, where all students are more likely to be required to take developmental classes. Not only are community colleges most likely to refer the same student profile to developmental classes, students of color are increasingly more likely to attend community colleges (Bailey, 2009) making them even more vulnerable to developmental placement, and therefore less likely of attaining college-level and completing a certificate or degree. These three factors--high numbers of students required to enroll in developmental courses, low rates of progress to college-level courses in the same discipline, and equity gaps in placement and completion--inform initiatives to reform traditional developmental education.

\section{Structural Reforms of Developmental Education}

Evidence that passing students drop out of the sequence between the end of one class and the start of the next and that others are discouraged by the long duration of 
developmental sequences has led community colleges to develop alternative models of developmental coursework. These alternatives challenge notions of how much time college students need to develop college-level writing and reading skills (Hodara \& Jaggars, 2014; Jenkins \& Cho, 2013). Reforms of developmental education have created ways for students to reduce the amount of time that they spend in developmental classes. Reforms include eliminating or reducing developmental requirements (Park et al., 2015), condensing course content so that students progress to college-level courses sooner (Edgecombe, Jaggars, Xu, \& Barragan, 2014), or granting access to college-level coursework earlier (Cho et al., 2012).

\section{Short developmental sequences.}

The compressed or accelerated model of developmental education (Edgecombe, Jaggars, Xu, \& Barragan, 2014) reduces a longer developmental sequence into a shorter period of time. CUNY colleges have both one semester and two semester developmental requirements that range from 6 to 12 units. Although the shorter course was not designed as a reformed model of developmental education, it offers the opportunity to compare the results of a shorter to a longer developmental requirement. Using a quasi-experimental design, Hodara \& Jaggars (2014) compare rates of enrollment and success in the developmental courses and at college-level between students in the one-course developmental model and the two-course model. 
Hodara \& Jaggars (2014) found that students in the shorter developmental requirement enroll in college-level English and passed it at higher rates than students in the long developmental sequence. The study drew on six years of institutional data and tracks students for a period of three years. Analyzing 11,430 student records, (Hodara \& Jaggars, 2014) found that fifty percent of students in the one-course model $(\mathrm{N}=1977)$ enrolled in college-level English whereas only $35 \%$ of students $(\mathrm{N}=2605)$ from the two course model. The two-course model also lost a greater number of students from the developmental-level to college-level, with 1693 students stopping before reaching college-level English. Of the students who enrolled in college-level English, $41 \%$ of students in the single course model passed the course compared to $29 \%$ of students from the two-course model. The shorter of the two developmental CUNY English requirements yields better results for students, assisting them in successfully completing college-level English.

\section{Accelerated courses.}

In contrast to the CUNY system faculty, English faculty at Chabot College, in Hayward, California intended to change the structure of developmental education when they began reforming developmental requirements. In the 1990s, Chabot College had six developmental English courses, three focused on teaching reading skills and three on writing. Faculty initially integrated these six classes and reduced them to three semesters, and later to two semesters of developmental English. Faculty continued their 
reform of developmental English by creating a one-semester accelerated model that prepared their students to succeed at college-level English. As a result of their innovation, Chabot students were able to complete developmental coursework in a single semester.

Chabot College's students have the option to accelerate their developmental coursework in a single semester or take the traditional two-semester sequence.

Edgecombe, Jaggars, Xu, \& Barragan (2014) analyzed Chabot's data from the inception of the Accelerated English program in Summer 1999 through fall 2010. Over a five-year period, students in Accelerated English were 20\% more likely to complete college-level English with a $\mathrm{C}$ or better $(\mathrm{N}=2642)$. Three-year rates of completion were similar. Of Accelerated students, $57 \%$ passed college-level English with a $\mathrm{C}$ or higher $(\mathrm{N}=3634)$, compared to $36 \%$ of traditional developmental students $(\mathrm{N}=2742)$.

Some Chabot program personnel attributed the success rates of Accelerated English to the opt in enrollment process. They thought that more highly motivated students were more likely elect to enroll in Accelerated English. In the first year, $45 \%$ of students (or 1734 students) in Accelerated English completed college-level English compared to $18 \%$ (or 856 students) in traditional development English, despite having a cohort that was $20 \%$ larger. This $27 \%$ difference is large. While Edgecombe et al. does not control for student motivation in their analytics, their descriptive analytics of the Accelerated student population $(\mathrm{N}=4593)$ and the traditional population $(\mathrm{N}=5321)$ and 
found that the students who elect to enroll in Accelerated English were quite similar to those in the traditional sequence. Accelerated students are more likely to be Asian (2\% more), attend full time ( $8 \%$ more), and have plans to transfer and earn a four-year degree ( $8 \%$ more). Controlling for these and other pre-existing student differences, Edgecombe et al., (2014) used a regression model and determined that students in the accelerated program were $17 \%$ more likely to successfully complete college-level English in five years. When Edgecombe et al., (2014) researchers used propensity score matching to control for differences, the students in the Accelerated Program were found to be $22 \%$ more likely to complete college-level English.

Chabot's rate of twenty percent more students from accelerated classes completing college-level English with a $\mathrm{C}$ or higher in five years is validated by the regression and matched set analysis. Furthermore, this analysis reflects a ten-year period of implementation, indicating that Chabot has sustained their success with the model.

\section{Accelerated Learning Program.}

Community College of Baltimore County (CCBC) implemented the Accelerated Learning Program (ALP). Whereas Chabot accelerates students from a lower-level developmental class to an upper-level developmental class, $\mathrm{CCBC}$ enrolls developmental students directly into college-level English. In the model, students who place just below the cut-off for college-level English, are offered the option to enroll in college-level English and co-enroll in a second course intended to support their learning in the college- 
level course. The co-requisite course provides students with additional time and support for reading and writing skill development.

The program outcomes achieved by ALP were a significant improvement over the outcomes of their traditional developmental English courses. Initial descriptive program data of 104 ALP students from the first three semesters showed that ALP students were $35 \%$ more likely to pass the first college-level English course, passing with a rate of $75 \%$ compared to $40 \%$ for the traditional developmental sequence. ALP students were also $22 \%$ more likely to pass the second college-level English course than developmental students who did not opt into the ALP (Jenkins et al., 2010).

Three years of program data with 592 ALP students showed similar results. ALP students maintained a pass rate of $74.66 \%$ and were $36 \%$ more likely to pass the first college-level course, and $20 \%$ more likely to pass the second college-level course than developmental students who did not choose ALP (Cho, Kopko, Jenkins, \& Jaggars, 2012). A regression analysis produced results that were close to the descriptive analytics (Cho et al., 2012).

ALP's high rates of success drew educators' and policy makers' attention to the program and resulted in replications. Some critics attribute the success of ALP to several factors, foremost being small class sizes. In CCBC's implementation of the model, English classes with ALP students mainstreamed are reduced to 20 students, 12 traditional college-level and 8 ALP (Cho et al., 2012). The three-unit co-requisite class 
that ALP students also take has only eight ALP students. The small class size of eight students is a drawback which poses affordability, staffing, and scalability problems for some colleges. Predictably, the size of the co-requisite class was one program feature that colleges modified in their replications of ALP. Goudas (2017) argues that the rapid level of acceptance and implementation of ALP is problematic due to the variations that implementers have developed that have not been validated by research.

\section{National Replications of ALP.}

The ALP model has been readily adopted and replicated by colleges, universities, and states including Arkansas, Colorado, Connecticut, Indiana, Michigan, and Virginia (Goudas, 2017). In 2014, Coleman published a study of the 137 programs that were replicating or modifying Baltimore's ALP model. Coleman's purpose is to describe the expansion of ALP in colleges and universities across the United States and to describe and assess these implementations of ALP. She describes the challenges of adoption in unionized settings, departments with different faculty designated for developmental and college-level, and addresses the challenges of scheduling and facilities that the corequisite model causes.

\section{ALP Implementation Fidelity.}

Despite the challenges of implementation, Coleman (2014) found that $85 \%$ of the replications used the $\mathrm{CCBC}$ model as designed, whereas $15 \%$ modified the model. By Coleman's publication date, $\mathrm{CCBC}$ had modified their model to allow up to twelve 
students in the co-requisite course, up from the original model of eight students. Of the twenty programs modifying CCBC's ALP model, eight implemented a model that joined ALP students from two college-level classes into one co-requisite class. With the enrollment in the co-requiste course doubled, the modification enabled colleges to implement and scale the adjusted ALP model. With $91 \%$ of the ALP replications using either the original CCBC model or the double-sized co-requisite model, it appears that Goudas (2017) overstated the variety across implementations of ALP, a primary argument in his critique of ALP adoptions. Coleman's description of replications showed that other key ALP features were evident in nearly all programs, for example, $97 \%$ of programs used the same instructor for both the college-level course and the co-requisite, a feature of CCBC's ALP model (Coleman, 2014).

\section{ALP Replication Outcomes.}

Coleman (2014) finds that ALP students had higher rates of success in the first and second college-level English course compared to non-ALP students, consistent with Jenkins et al., (2010) and Cho et al., (2012). Drawing on program data from four colleges with different scales of adoption, levels of support from CCBC, and amount of professional development for faculty, Coleman (2014) finds that these schools dramatically changed outcomes in success in the first college-level English class.

Coleman drew on four cohorts of ALP students $(\mathrm{N}=336, \mathrm{~N}=98, \mathrm{~N}=228$, and $\mathrm{N}=267)$ that had more students than the initial studies of CCBC. ALP students in three of the four 
colleges passed the first college-level English class at rates of $78 \%$ compared to success rates ranging from $34 \%-50 \%$ prior to implementation of ALP.

Unlike the transfer pathway in California community colleges, none of the four colleges that Coleman uses to study rates of student success requires a second collegelevel English class. For this reason, there are low rates of enrollment in the second college-level English class. Of those students who elected to continue in English classes, ALP students achieved rates of success three to six percentage points higher than their non-ALP peers: ALP students enrolled and succeeded at rates of $17 \%$ compared to $12 \%$, $19 \%$ compared to $13 \%, 23 \%$ compared to $20 \%$, and $41 \%$ compared to $35 \%$.

Tennessee statewide ALP adoption. The ALP model was first piloted at all twoand four-year public institutions in Tennessee in 2013 in an effort to deal with systemwide high rates of developmental placement and low rates of developmental success (Denley, T. \& Knox, P., 2016). Data from the Tennessee Board of Regents (TBR) shows that in $2012,60 \%$ of students in the Tennessee higher education system placed into developmental courses, but only $30 \%$ successfully completed developmental requirements and passed college-level English. In the first year of the ALP pilot, success rates in college-level English doubled from 30\% to more than $60 \%$ (Denley, T. \& Knox, P., 2016). In 2015-16, the TBR reported that the pass rate for those students enrolled in ALP English increased from $31 \%$ to $62 \%$, with $58.7 \%$ passing college-level English the first semester. Although the TBR does not report actual numbers or disaggregate their 
data, they reported that the doubling of success rates was apparent across the full student population (Denley, 2016). The levels of success achieved in Tennessee are consistent with other implementations of the ALP model.

Equity and ALP. ALP has potential to support higher rates of success in collegelevel English for African-American, Latinx, low income, and other students who are historically underrepresented in higher education. Although (Coleman, D., 2014) does not report the number of black or Hispanic students in the ALP at these institutions, her study shows that the overall rates of success in ALP are also achieved by African American and Latinx students, but to varying degrees. In her focused study of four ALP replications, Coleman (2014) shows that whereas a modest gain of $8 \%$ in the success rate in collegelevel English among African American and Latinx students occurs at one institution, others increased from $25 \%$ to $70 \%$, from $26 \%$ to $66 \%$, and from $46 \%$ to $76 \%$. One institution achieved equitable pass rates of $76 \%$ within their ALP program, and two colleges reduced gaps by $5 \%$ and $6 \%$, whereas the college with a gain of $8 \%$ for African American and Latinx students saw a gain of $24 \%$ for white students.

\section{Critiques of Developmental Reform.}

An important criticism of traditional developmental education is that students do not complete developmental sequences. Goudas \& Boylan (2012) counter this critique by arguing that traditional developmental education is effective for students who persist in the sequence. Further, they posit that it is not reasonable to evaluate developmental 
education on the basis of attrition. In their critique of Cho et al. (2012) and Jenkins et al., (2010), Goudas \& Boylan (2012) question research that compares a one-semester accelerated developmental class to a traditional two-course sequence, stating that attrition, not developmental education, leads to poor outcomes in the two-course model.

Critics of traditional developmental English agree that attrition is a primary threat to success in developmental completion (Bailey, 2009; Hern, 2012; Jenkins et al., 2010). As noted earlier, students who pass courses in the developmental sequence do not always enroll in the subsequent course; thus, attrition is the fundamental problem that acceleration addresses. Goudas \& Boylan (2012) minimize the differences between acceleration and traditional developmental English when they insist on making class-toclass comparisons. The comparison of a one course requirement to a two (or more) course requirement is a necessary comparison of different developmental programs.

To support the claim that traditional developmental English can work, Goudas (2017) offers CUNY's ASAP model as an example. ASAP offers traditional developmental classes at the beginning of a student's college enrollment. However, it also has other key program features such as full-time enrollment, counseling, tutoring, and robust financial support including books and transportation that contribute to its success. By providing this model as an example, Goudas inadvertently contradicts his own argument, and illustrates that evaluations of developmental education should not be focused singly on classes. Rather when we evaluate developmental English, we are 
evaluating programs, and to be meaningful and accurate, our evaluation must reflect descriptions of all of the program components. In conclusion, the critiques offered by (Goudas, A., 2017; Goudas \& Boylan, 2012) are not convincing. The successes of acceleration and the co-requisite model warrant attention and replication.

Florida developmental policy. State policy makers are increasingly aware of the poor efficacy of developmental education. The impact of developmental education on college completion and the workforce has interested legislators and resulted in policy that informs the structure of developmental education in 2- and 4-year state institutions. Florida's Senate Bill 1720 made developmental education optional for active duty military and Florida's high school graduates, effectively restructuring developmental education in Florida's public higher education system in 2013. Park et al. (2015) study investigates the impact of the opt-in policy on developmental enrollment patterns in its first year. Park et al. (2015) find that rather than encouraging students to enroll directly in college-level coursework, the opt-in developmental policy results in many students with optional developmental placements in a subject not enrolling in developmental or college-level coursework in that same subject.

Park et al. (2015) analyze 8,779 students from two colleges in the 28-college Florida system. Of these students, $21 \%(\mathrm{~N}=1843)$ were recommended for developmental reading, but only $8 \%$ enrolled. Of the remaining $92 \%, 36 \%$ percent of these students opted to enroll in college-level reading, but the majority, $56 \%$, did not enroll in a reading 
course at all. Similarly, $24 \%(\mathrm{~N}=2106)$ of students were recommended to take developmental writing, and $41 \%$ opted not to take writing at all in their first-year of coursework. Unlike students recommended to take developmental reading, more students enrolled in developmental writing, with $31.5 \%$ of those recommended for developmental writing enrolling in the course, and only $27.5 \%$ enrolling in college-level. A subsequent study of Florida's optional developmental policy showed that even more students opted out of developmental coursework. Whereas $41 \%$ in 2014 chose not to take developmental English, up to 48\% of students enrolled in 2014-15 opted out Woods, Park, Hu, \& Bertrand Jones (2017). It is possible that in the second year of the policy, more students were aware of their option to skip developmental recommendations.

Cooper et al., (2017) demonstrate that in California community colleges, there are some students who are unable to graduate due to having delayed completion of English and math requirements. In even greater numbers, Florida's optional developmental requirements result in students who are accumulating college credits without meeting requirements in college-level English. Park et al. (2015) demonstrate that Florida's Senate Bill 1720 is effective for students who place just below college-level. However, the large numbers of students who do not enroll in developmental or college-level English suggest that developmental reform could more effectively meet their needs than Florida's current opt-out policy. 


\section{Curriculum and Pedagogy Reform}

Most of the research on developmental reform is quantitative and focuses on rates of student success at the college level. However, when structural reforms are complemented by faculty-led reform of curriculum and pedagogy, the effects can be significant and long lasting (Edgecombe, Cormier, Bickerstaff, \& Barragan, 2013). If colleges are interested in implementing more than a structural change, Coleman (2014) draws the conclusion that faculty will need buy-in, additional support, and opportunities for collaboration and professional development. More specifically, Grubb \& Gabriner, (2012) demonstrate that lasting reforms are achieved not by structural changes alone, but take hold when faculty are engaged in practices that change their teaching as well. At Chaffey College in Rancho Cucamonga, California, reforms to Basic Skills were supplemented with support for faculty with teaching and learning.

Through the reform process, English faculty at Chabot College in Hayward, California realized that their courses need to integrate reading, writing, and student success skills, so that students would "feel comfortable" and confident in the academic space (Edgecombe et al., 2014, p. 8). Edgecombe et al. (2014) found that Chabot's faculty engaged in a process of reform that yielded a shared set of principles that guide pedagogy and practice. Likewise, Coleman (2014) observes that the difference between the traditional developmental goal of getting students ready for college-level coursework and the ALP aim of helping students pass college-level coursework is philosophically and 
pedagogically a different undertaking — one that constitutes a paradigm shift. This dissertation is a case study of a college shifting paradigms. By casting off the structural remnants of the traditional remedial paradigm, Cloudline College aligned its philosophy and pedagogy with its belief that all high school graduates are capable of completing college-level English successfully. When the college reformed its developmental structure, faculty shifted from a paradigm that reproduced inequity to a paradigm that promotes equity.

\section{Gaps in the Research}

Research on accelerated English has focused on the ALP model. More has been written about CCBC's implementation of the model than has been written about other colleges and universities replications of ALP. Coleman (2014) calls for additional research on the implementations that take place in colleges other than $\mathrm{CCBC}$ to assist more colleges with their replications or modifications. She calls specifically for case studies, believing that "we will gain a deeper understanding of the myriad of ways that colleges can adopt and adapt it and make it their own" ultimately successfully institutionalizing it at colleges across the country. Coleman's call for colleges to make ALP their own, brings to mind Goudas' (2017) concern that modifications are being made without research or validation. As colleges modify ALP, whether to make it sustainable, bring it to scale, or tailor it to their students and institution, it is important to study the impact of modifications to the model. 
The majority of what has been written about the ALP has focused on quantitative assessments of program success. Coleman (2014) calls for case studies to learn more about the underlying curriculum, pedagogy, and professional development that leads to student success. Qualitative research that addresses how administrators and faculty have developed and implemented accelerated English at their institutions will help those who are responsible for implementing change and add to a body of knowledge that supports reforms of developmental English.

The findings of this research answer Coleman (2014) for contributions to the body of research on developmental English reforms. Whereas the quantitative findings in Chapter Four of this dissertation provide similar information to existing research on ALP Cho et al. (2012) Chapter Five and the qualitative findings on the faculty experience of implementing the reform provide a new perspective, which directly fulfills the need Coleman (2014) cites for curriculum, pedagogy, and professional development that leads to student success. 


\section{Chapter Three: Methodology}

\section{Introduction}

This research is a case study of the implementation of English 105 . The research was guided by three questions that studied the impact of a structural change in developmental English at Cloudline College. The questions look at the impact of a change in program structure on faculty practice and student success. This chapter includes a discussion of my research questions, methods, and design. Additionally, I provide a description of the site of the intervention, Cloudline College, and the local and state contexts surrounding the implementation of English 105. I follow my discussion of the contexts with a discussion of the samples and populations and conclude with a discussion of the data.

\section{Study Design}

This research uses a concurrent multiple methods design which studies the impact of structural changes associated with the English 105 program. While this study does not constitute a formal program evaluation, this research evaluates the impact of two key elements of the English 105 program, structural change and community of practice.

The rationale for the study stems from an effort to evaluate the success of program components for the purpose of program improvement. This research was conducted early during the implementation and scaling of English 105. The research design conforms to Cloudline College policies and practices. Thus, the research design 
was constrained to a non-experimental design because it was not feasible or ethical to construct an experimental design. A random assignment of faculty to teaching assignments would present ethical and contractual issues. A random assignment of students to classes would not have been ethical or possible within the course registration process that provides students with choice and agency.

To evaluate the impact of the structural change in developmental English on faculty practice and student success in the English sequence, I designed a concurrent, multiple-methods study. I used quantitative methodology to research student success in the English. I collected data on student success in the three English sequences: the traditional developmental (English 846, 100, and 110), the traditional college-level (English 100 and 110), and the intervention (English 105 and 110). Using descriptive analytics, I compared English 105 data to traditional developmental and college-level program data.

During the same time that I drew student success data, I collected data on the impact of the structural change on faculty. Using qualitative methods, I researched the impact of participation in a community of practice on faculty responses to the structural change. I extracted qualitative data from English 105 artifacts, and conducted focus groups and interviews with English 105 faculty. Combined, my research on student success and faculty practice provide an evaluation of the impact of a structural change in 
developmental English, which is a first step in evaluating the effectiveness of this programmatic change.

\section{Role of the Researcher}

My position as the dean for Language Arts at Cloudline College significantly contributed to my ability to conduct the study. Following the college's adoption of new placement standards and processes, I served as a thought partner to English faculty who developed the vision for English 105. I supported their work by providing partial reassignment from teaching for the faculty coordinator of English 105 to allow him to develop curriculum and coordinate the community of practice. I sought and attained approval for the community of practice, including financial compensation for participating faculty. Finally, I supported English 105 work by scheduling only those faculty members who completed the community of practice to teach the course. My support for English 105 ensured implementation of the project.

My role as dean gave me excellent access to faculty to conduct qualitative research. I had regular meetings with the English 105 coordinator to discuss the course and the community of practice. English 105 faculty could drop by my office at any time to discuss the course or the Community of practice. Because I shared the workplace with English 105 faculty, it was easy for me to have access to program artifacts, the Community of practice itself, and time to conduct interviews or focus groups. 
A trusting and communicative work environment within the Language Arts division enhanced my access to English 105 faculty members. As dean, I have created a safe environment for faculty to express themselves openly and honestly. Faculty are as likely to discuss challenges they face in teaching English 105 as they are to discuss successes. This level of trust is enhanced by my openness in sharing my own challenges as a former English faculty member. English instructors know that there is no judgement when they open up about the difficulties of teaching. For this reason, my interviews and focus groups produced reliable information about the experience faculty had adjusting to structural changes in developmental English.

To ensure that qualitative data was ethically obtained, I made the faculty aware that the English 105 course and the community of practice are topics of my research. I have provided instructors with candid explanations of the research, and provided disclosure forms, although it is not required by IRB standards. Faculty who elect to sign the forms have created their own pseudonyms and given me permission to quote them. Faculty members who did not wish to be quoted, simply did not return the forms. All faculty who participated in the community of practice elected to do so, and they were paid according to the district contract for their participation in the community of practice. 


\section{Research Questions and Sub-Questions}

The research questions focus on two key elements of English 105, faculty responses to the structural change, and student success in the course. As previously discussed in Chapter One, the research questions are:

1. How do structural changes affect rates of student success in a reform of the English developmental course sequence? This question evaluates the rates of success that students achieved in English 105. English 105 rates of success are compared to rates of success achieved by students whose first English class is English 846 (developmental English) and English 100 (traditional college-level English). All data is disaggregated to determine if the intervention has any impact on equity. Sub-questions include:

a. What are rates of completion of English 105 with an A, B, or C among students who enroll in English 105?

b. What are rates of completion of English 110 with an A, B, or C among students who complete English 105?

2. What challenges do the faculty of college-level English face as a result of structural changes in developmental education? This question seeks to understand how instructors experience the structural change in developmental English. The structural change reclassifies groups of students who would have been placed in developmental classes under the previous placement standards and places them in college-level English. 
3. How does participation in a community of practice impact faculty responses to structural changes in developmental education? This question seeks to understand from the faculty perspective what impact, if any, participation in the community of practice has on their response to the structural change in developmental English.

\section{Context}

\section{Cloudline College.}

One of three community colleges in the San Mateo Community College District, Cloudline College is well-funded. Located in Silicon Valley, San Mateo County produces local funds for education from high property taxes. When local funds exceed the state's apportionment, local funds go to K-12 and community college districts, resulting in districts that are referred to as basic aid or community-funded. As a result, Cloudline College and other community-funded colleges are funded at a higher rate than apportionment-funded California community colleges. In 2011, local property taxes provided an additional \$2,200 per pupil in community-funded districts (Public Policy Institute of California, 2013). As a point of comparison, in 2018, per student funding in other community colleges is $\$ 8645.00$ (Community College League of California, 2018). These community funds provide financial flexibility that Cloudline College leadership opts to use to provide reassignments to faculty to coordinate new programs and to pay faculty for their participation in extended professional development. 


\section{Student Population.}

Cloudline College serves a diverse population of approximately 10,000 students annually. In Fall 2017, enrollment totaled 9221 students (Cloudline College Fact Sheet 2017-18). Predominately enrolled part-time (Table 2), the student body is almost equal parts Filipin@, Asian/Pacific Islander, Latinx, Mulii-race, and white (Table 3).

Table 2

Cloudline College student enrollment status

\begin{tabular}{lll} 
Enrollment status & Number & Percent \\
\hline Part-time & 6547 & $71 \%$ \\
Full-time & 2674 & $29 \%$
\end{tabular}

Note. Fall 2017 enrollment data shown

With nearly $75 \%$ of all Cloudline College students attending part-time (enrolled in fewer than 12 units), the ability to advance to college-level English more quickly is particularly impactful. English 105 reduces the time that part-time students are at the college by a minimum of one semester.

Table 3

Cloudline College student racial and ethnic demographics

\begin{tabular}{|l|l|l|}
\hline Ethnicity & Number & Percent \\
\hline American Indian/Alaska Native & 9 & $0.1 \%$ \\
\hline Asian & 1660 & $18 \%$ \\
\hline Black Non-Hispanic & 277 & $3 \%$ \\
\hline Filipin@ & 1660 & $18 \%$ \\
\hline Hispanic/Latinx & 1752 & $19 \%$ \\
\hline Multi-race & 1844 & $20 \%$ \\
\hline
\end{tabular}




\begin{tabular}{|l|l|l|}
\hline Pacific Islander & 92 & $1 \%$ \\
\hline Unreported & 184 & $2 \%$ \\
\hline White Non-Hispanic & 1752 & $19 \%$ \\
\hline
\end{tabular}

Note. Fall 2017 data shown

The potential positive impact of acceleration stands to benefit many Cloudline College students. In 2012, more than half of all Cloudline College students began college placed in developmental English. Latinx and Filipin@ students, together 40\% of the Cloudline College population, are likely to be overrepresented in developmental classes.

Half of the Cloudline College student population is 18-24 years old (Table 4), and just slightly more than half identify as female (Table 5).

Table 4

Cloudline College student age demographics

\begin{tabular}{lll} 
Age Group & Number & Percent \\
\hline $0-17$ & 369 & $4 \%$ \\
$18-22$ & 4795 & $52 \%$ \\
$23-28$ & 2121 & $23 \%$ \\
$29-39$ & 1199 & $13 \%$ \\
$40-49$ & 368 & $4 \%$ \\
$50-100$ & 369 & $4 \%$
\end{tabular}

Note. Fall 2017 data shown

Table 5

Cloudline College student gender demographics

\begin{tabular}{lll} 
Gender & Number & Percent \\
\hline Female & 4795 & $52 \%$ \\
Male & 4242 & $46 \%$
\end{tabular}


Unreported

184

$2 \%$

Note. Fall 2017 data shown

Generally speaking, the Cloudline College population is young, with $79 \%$ of the population less than 29 years of age. Younger students are more likely than older students to pursue transfer and to need to enroll in college-level English, a requirement for transfer.

Leadership and equity. Cloudline College faculty and administration alike draw impetus for their leadership from an urgent desire to produce equitable student outcomes. Cloudline College's Comprehensive Diversity Framework is a value statement and planning document that affirms the college's regard for diversity and commitment to equity. The framework states that "Ensuring diversity and equity at all levels of the institution promotes Cloudline College's mission and strategic priorities, enriches curricular content and pedagogical approaches, deepens critical thinking, enhances cultural fluency, strengthens campus community, and increases student success" (p. 5). The college's focus on equity served as a foundation for the English department's work on acceleration.

English department and equity leadership. The faculty of the Cloudline College English Department are guided by their commitment to equitably serving students in a data-informed manner. Prior to their work on English 105, the faculty had engaged in other work that was informed by data and motivated by their desire for equity. The 
faculty engaged in a previous acceleration project, which granted access to a course onelevel below transfer to students who were placed two levels below. This work nearly eliminated enrollment in the course two levels below transfer, and increased rates of success in the course one level below transfer.

Open source textbook. The development of a free textbook was another example of English faculty serving students in a manner informed by data and equity. Faculty were informed that the high cost of textbooks prevented many students from having textbooks and contributed to equity gaps. As a result, English faculty developed a free, online composition textbook that was adopted for use in English 846, 100, and 110. English faculty invited collaboration with librarians, who contributed to a section on research, and ESL faculty who ensured that the needs of English language learners were addressed throughout the text. The English faculty's work towards equity expanded their capacity for collaboration and leadership.

Equitable placement. The English faculty used collaborative leadership skills to begin work on English 105. In meetings with English faculty from feeder high schools, Cloudline College English faculty found evidence of strong alignment between high school and college curriculum. Through these discussions, faculty learned that students who had earned B's and C's in high school English were often placed in developmental English when they arrived at college. 
Informed by high school writing outcomes, and with evidence of inaccurate English placement, two English faculty members led discussions with the full faculty to consider lowering placement scores required for college-level placement. College data provided evidence that lower placement scores would create more equitable placement at college-level. As a result, English faculty decided to lower cut scores for students who took the placement test. They also agreed on high school grades and GPA requirements for placement into college-level English and collaborated with counseling to implement transcript-based placement. With equity as a lens and data to inform decision making, English faculty provided leadership to provide students equitable placement into collegelevel English.

Collaboration with ESL faculty. Equitable outcomes for ESL students were enhanced by collaboration between ESL and English faculty. To ensure a smooth transition from developmental ESL classes to college-level English classes, several ESL faculty teach both ESL and English. The addition of English 105 provided ESL students two college-level courses to choose between, the traditional, three-unit, English 100 and the new, five-unit English 105. As many ESL students wanted the course with additional support, and ESL faculty felt as though their students would benefit from the additional time and support, ESL faculty prepared to teach English 105 by participating in the English 105 community of practice. Some ESL faculty who would not be teaching English 105 participated in the community of practice to enhance their alignment to the 
course. Additionally, the collaboration with ESL faculty served to make English faculty more aware and skilled in their teaching of ESL students who have matriculated to college-level English. Collaboration between faculty teaching English and ESL enhanced instruction in both subjects and served students more effectively.

Traditional English sequence. Prior to the structural reform, the college-level English sequence consisted of two three-unit courses, English 100 and English 110. However, as Table 6 shows, slightly less than half of the incoming student population had to complete a developmental English course prior to beginning the college-level sequence. English 846 is a five-unit developmental course, one-level below college level.

Table 6 Cloudline College traditional English sequence

\begin{tabular}{|l|l|l|}
\hline Placement & Sequence & Percent \\
\hline College-level & $100+110$ & $51.64 \%$ \\
\hline Developmental & $846+100+110$ & $48.35 \%$ \\
\hline
\end{tabular}

Note. Fall 2012-Fall 2015 data shown

English 100 is the first college-level course and is required for Associate's degrees and transfer. Students who are placed at college level in the traditional model begin with this class. Students who are placed at a developmental level can enroll in English 100 after passing English 846, although some do not enroll in English 100 despite completing English 846 successfully. The traditional sequence culminates with English 110. The 
course is not required for the Associate's degree, but most students seeking the AA, AS, or transfer enroll in the course.

English 846 enrollment. The disproportionate pattern of enrollment of some racial groups in English 846 demonstrates inequitable access to college-level English. As seen in Table 7 below, American Indian, African American, Filipin@, Latinx, and Pacific Islander students are overrepresented in the English 846 population compared to the total population. Asian and white students do not enroll in English 846 in proportion to their representation in the total population.

Table 7

Equity and access to college-level English

\begin{tabular}{|l|l|l|l|}
\hline Ethnicity & College Pop. & Engl. 100 & Engl. 846 \\
\hline American Indian & $0.1 \%$ & $0.09 \%$ & $1.6 \%$ \\
\hline Asian & $18 \%$ & $21.8 \%$ & $12.9 \%$ \\
\hline Black Non-Hispanic & $2.9 \%$ & $2.56 \%$ & $4.96 \%$ \\
\hline Filipin@ & $18 \%$ & $18.92 \%$ & $23.35 \%$ \\
\hline Hispanic/Latinx & $19 \%$ & $15.85 \%$ & $23.82 \%$ \\
\hline Multi-racial & $20 \%$ & $19.81 \%$ & $21.16 \%$ \\
\hline Pacific Islander & $1 \%$ & $1.01 \%$ & $2.05 \%$ \\
\hline Unreported & $2 \%$ & $1.6 \%$ & $0.73 \%$ \\
\hline White Non-Hispanic & $19 \%$ & $18.3 \%$ & $10.87 \%$ \\
\hline
\end{tabular}

Note. Fall 2012- Fall 2015 data shown, N=7838 (Engl. $100 \mathrm{~N}=4048$, Engl. $846 \mathrm{~N}=3790$ )

Implementing English 105 is one means of ensuring that access to college-level will be equitable.

Reformed English sequence. Developed by faculty for the structural reform, English 105 fulfills the requirement for the first college-level course. English 105 curriculum has the same student learning outcomes as English 100, but its pedagogy is 
intended for students who would previously have been placed in a developmental course. Rather than a three-unit course, English 105 is a five unit course that gives students and faculty more time together with the course content.

The English 105 curriculum differs from English 100 by developing affective domain outcomes. English faculty reinforced cognitive learning outcomes with affective domain outcomes that were informed by Diego Navarro's work with ACE Academy and reported on in Booth (2013) Student Support (Re)Defined. The emphasis on affective domain is reinforced in course materials, policies, practices, activities, and faculty mindset. Affective domain outcomes have been developed and tested, but have not been adopted as outcomes on the official course outline. Formal curriculum revision is planned for Fall 2018.

Table 8

Reformed Cloudline College English sequence

\begin{tabular}{|l|l|l|}
\hline Placement & Sequence & Percent \\
\hline College-level & $100+110$ & $50.79 \%$ \\
\hline Developmental & $105+110$ & $49.20 \%$ \\
\hline
\end{tabular}

Note. Fall 2017 data shown, $\mathrm{N}=821$ (Engl. $100 \mathrm{~N}=411$, Engl. $105 \mathrm{~N}=404$ )

Accelerated English 105, shown above in Table 8, gives nearly all students the opportunity to complete the first college-level course in a single semester and the collegelevel sequence in two semesters. In the traditional developmental English sequence, nearly half of the student population requires at least three semesters to complete the sequence. In the accelerated model, no student is delayed by additional requirements. 
California Acceleration Project. The California Acceleration Project (CAP) expanded the leadership expertise of Cloudline College faculty and provided a model for professional development. CAP, a faculty-led professional development network, supports community college efforts to transform remediation and increase equitable student completion. CAP provides accelerated models for reforming remedial English and Math, professional development for departments interested in reform, and leadership development based on a train-the-trainer model. Cloudline College's English 105 faculty coordinator participated in CAP organized communities of practice on implementing and leading acceleration.

Cloudline College's community of practice. The California Acceleration Project convenes communities of practice across the state with community college faculty to build their understanding of acceleration and to provide support for system change. Cloudline College faculty participated in CAP's first cohort of the community of practice and engaged as leaders in subsequent cohorts. Following his participation in CAP's leadership training, Cloudline College's coordinator of English 105 was prepared to coordinate Cloudline College's community of practice.

CAP's success with the community of practice model led to Cloudline College adopting community of practice to support its transition to an accelerated, college-level English class. Faculty who request to teach English 105 must participate in the English 105 community of practice. The English department has provided a community of 
practice every semester since English 105 classes were introduced at scale, in Fall 2016. Although the first cohort was exceptionally large at 18 instructors, subsequent cohorts have been an ideal size of approximately 8 faculty members. The English department's desire to implement English 105 and quickly bring the course to full scale meant that many instructors were interested in participating in the first cohort. Subsequent cohorts were comprised of faculty members to the new department and those who were unable or not interested in participating in earlier cohorts.

In addition to building understanding of acceleration principles, participation in the community of practice expanded leadership skills among the Cloudline College English faculty. In the same manner that participation in the CAP community of practice led to leadership among Cloudline College participants, engaging in the Cloudline College community of practice provided leadership growth opportunities for interested Cloudline College faculty members. The community of practice provided an environment conducive to developing leadership. The Community of practice was structured, inclusive, and supportive, and content was repeated from one cohort to the next, making it an ideal context for emerging faculty leaders to practice leadership.

Student Participant Selection. Student records for any student enrolled in a Cloudline College English class at any time between Fall 2012 and Fall 2017 were used to answer the research question about student success. Students were not directly involved in the research. 


\section{Quantitative Data Collection}

Quantitative data for the study was collected in January 2018 for the period between Fall 2012 and Fall 2017. Cloudline College's office of research provided raw data of all English enrollments from Fall 2012 through Fall 2017 which totaled a sample of 25,286 records. This data was cleaned resulting in a final sample of 24,544 .

Incomplete grades were removed from the original sample because they do not indicate failure or success in course completion. Additionally, English 846 data was collected only for the period prior to implementation of English 105. This limitation resulted in 737 records being removed from the initial sample.

Data within this sample focused on students and their success in English. Data included students' initial English enrollment and all subsequent English enrollments and course grades. Additionally, student-reported age, gender, and race or ethnicity were also collected. Data was not collected on student financial aid status or participation in learning communities or other support programs. Data was not collected on instructors or a course's affiliation with a learning community.

It was not the purpose of this research to study differences among instructor rates

of success. Administrators and faculty members are aware that student success rates vary among instructors. While there are variations within an individual instructor's rates of success, there are also differences from instructor to instructor. In some cases, analysis of instructor-level interactions would disclose the identity of an instructor. As a 
researcher, I am responsible for ensuring the privacy of those participating in the research. As the dean responsible to English faculty and their students, I determined that this research was not the appropriate place to address instructor-level interactions.

Internal validity. Cloudline College's primary purpose for implementing English 105 was to increase equitable access to and success in the first college-level English course. The quantitative data generated for this research has internal validity in determining that equitable access and success improved. Descriptive statistics were used to determine if there was any improvement, and analytical statistics was used to determine if any improvement can be attributed to English 105.

T test. Prior to data analysis, it was determined that a $t$ test would be useful to determine the difference in means among student success in English 846, English 105, and English 100. It was also determined that a $t$ test would be useful to determine the difference in means between the success rates of white and Asian students compared to minoritized students, including American Indians, Alaska Natives, African Americans, Filipin@s, Latinx, and Multi-race students.

Regression analysis. A recursive conditional inference tree was used to determine which variables were most significant in a students' success in English. Levshina (2015) explains that conditional inference trees determine if any independent variables are associated with the dependent variable, and produces the variable that has the strongest association with the response. Tagliamonte \& Bayen (2012) argue that 
conditional inference trees are useful in situations where the value of $\mathrm{N}$ is small relative to the number of independent variables. Conditional interference trees are also useful when independent variables may be highly correlated.

Confounding variables. Factors related to English 105 but not considered in the research questions or reflected in the data collection may be confounding variables including learning communities, instructional faculty, and grade inflation.

Learning communities. Cloudline College provides learning communities for students to enhance community and provide additional support academic and cocurricular support. Learning community data was not collected for this research, nor was it the subject of this research. However, many Latinx, African American, and Filipin@ students participate in the Puente, Umoja, and Kababayan learning communities that are planned to serve them. The impact of English 105 on Latinx, African American, and Filipin@ students and equity is the subject of this research. For this reason, possible interaction of English 105 rates of success with learning community enrollment is a consideration.

English 846 is among the first classes that learning community students take. While English 846 was implemented consistently across learning communities, English 105 was not, for reasons particular to each learning community. The implementation of English 105 was determined by the learning community faculty who tried to anticipate the needs and consider the interests of their students in their decisions. The Umoja 
learning community continued to offer English 846 and did not offer English 105. Puente offered both English 846 and 105, which meant that students did not progress through English at the same rate. Kababayan implemented English 105 for all students. As a result of these different implementation decisions, the impact of learning communities on English 105 was inconsistent. Umoja students took English with nonlearning community faculty. Puente students had two cohorts in their learning community: a developmental cohort and a college-level cohort taught by different instructors. It is possible that this inconsistent implementation played a part in the outcomes of African American and Latinx students in the English 105 data. With the research on English 105 available to all learning community faculty and coordinators, effective Fall 2018, English 105 will be offered in all learning communities.

Instructional faculty. The impact of individual instructional faculty may be a confounding variable among some student groups. As noted above, Umoja students who originated in English 846 had one faculty member for all of their English classes. With the implementation of English 105, Umoja students did not have the opportunity to take English 105 as part of the learning community. Therefore, these students enrolled in nonUmoja English classes. As a result, African American English 846 students were highly likely to have had English with one instructor, whereas African American English 105 students were likely to have taken English with a wide variety of instructors. This 
instructional difference could confound results for students in the Umoja learning community.

Grade Inflation. The rate of student success in English 105 could be inflated. It was possible that the Hawthorne effect (Landsberger, 1958) could result in faculty awarding higher grades to student work produced in English 105. The course and the faculty are the subjects of this research, and for that reason it is possible that faculty could teach with an awareness of this research and evaluate English 105 students differently. To determine if grade inflation was contributing to rates of success, English faculty conducted a blind reading and evaluation of English 105 papers and English 100 papers in Fall 2017.

The Language Arts division office organized the blind process. In every English 100 and 105 class taught at Cloudline College in Fall 2017, three student essays were randomly selected. Random numbers from an online random number generator were used to identify three students from each class roster. Faculty submitted the third paper written by the randomly selected English 105 and 100 students. These papers were prepared for the blind reading by assigning the paper a number which allowed it to be tracked, and removing evidence of course, instructor, and student. Papers were combined into packs for the evaluators who were faculty from English 100 and 105. Packs were assembled and assigned to ensure faculty did not read their own papers. Evaluators 
assessed the papers in their packs, assigning a pass/no pass grade. Each paper was read by two evaluators, and their grades were compared to the instructor's grade on the paper. The grade inflation analysis revealed that while there was some grade inflation in English 105 assessment, it occurred at the same rate as grade inflation in English 100. This analysis ruled out grade inflation as an interference with the results of this study.

External Validity. This research should not be regarded as generalizable. This research was conducted as a case study, intended to inform Cloudline College about the implementation of English 105 and guide program improvement. A secondary purpose of this research is to add to the body of work on acceleration, the co-requisite model of English, and, finally, to enhance understanding of the co-requisite model implemented in this specific context.

\section{Faculty Participant Selection}

English 105 faculty were selected to participate in this research in order to address research questions about the challenges faculty face as a result of structural changes in developmental education and how faculty are impacted by their participation in a community of practice. Participants in the English 105 community of practice study include all faculty members in the first and second cohort of the community of practice, which were conducted in Fall 2016 and Spring 2017. These two cohorts were comprised of 10 full-time and 15 part-time faculty members. English faculty made up 19 members, whereas the remaining six taught ESL or both ESL and English. Faculty who identify as 
female outnumbered those who identify as male, 18 to seven. The racial identity of most of these participants is white. Three identify as Filipin@, one as Asian, and one as Multirace. The two cohorts are representative of the departments.

All cohort members contributed to the artifacts that were collected and analyzed for this research. Faculty members from the second cohort of Cloudline College's community of practice participated in a focus group. Five faculty members were selected for interviews: the faculty coordinator, a volunteer faculty leader, and three faculty members who felt as though the community of practice contributed to their professional development.

\section{Ethics and Protection of Human Subjects}

This research is considered exempt because I conducted it as part of my normal educational practice in overseeing the implementation of the program; however, to address any ethical concerns, faculty members could opt out of the study or elect to participate anonymously. I informed all English 105 faculty of the research that I was conducting, and provided them with explanations of the research. I provided disclosure forms, although it was not required by IRB standards. Faculty who elected to sign the forms, created their own pseudonyms and gave me permission to quote them. Faculty members who did not wish to be quoted, simply did not return the forms. All faculty who participated in the community of practice elected to participate, and they were paid according to the district contract for their participation in the community of practice. 


\section{Qualitative Data}

Program artifacts. Qualitative data were gathered from faculty participating in the community of practice. Informed by Charmaz (2014), I have used grounded theory to analyze program artifacts, focus groups, interviews and memos. I drew on 50 pages of extant and elicited documents collected from two cohorts of communities of practice collected in conducted in Fall 2016 and Spring 2017. These documents included applications to participate in the Community of practice, meeting agendas, faculty meeting notes, and letters written to new cohort members at the conclusion of the Community of practice. Elicited documents include reflections on the Community of practice experience written at the program end. I employed descriptive coding except in the cases where the faculty developed their own terms to refer to key concepts of their work. In these cases, I use in vivo codes (Saldaña, 2013) in order to preserve participants' language and meaning. In vivo codes are particularly appropriate where community members have developed a shared sense of meaning in their work that they reflect in a common language.

Focus group. A focus group was an effective means of capturing a shared sense of the experience of teaching English 105 and participating in the community of practice.

I recorded and transcribed a 90-minute focus group with the Spring 2017 cohort of the Community of practice. This cohort was the second cohort facilitated in the college's process of bringing English 105 to full scale. The second Community of 
practice reflected changes and learning that took place as a result of facilitating the first Community of practice. The experience of being a member of the community of practice in subsequent cohorts was is captured in the second cohort.

Interviews. Interviews were used to understand how participation in a community of practice impacted faculty responses to structural changes in developmental education. Purposive sampling was used to document and understand the experiences of cohort members who changed their teaching as a result of their participation in the Community of practice. These participants identified themselves as having made what they considered to be significant changes in their teaching practice. Creswell \& Plano (2011) describe purposive sampling as a process of identifying and selecting individuals or groups of individuals that are especially knowledgeable about or experienced with a phenomenon of interest. The experience that this sample of instructors had in the community of practice can provide insight on how to facilitate a community of practice to produce transformation.

Sample and coding. Interviews were conducted with four faculty members who identified themselves as changing their teaching practice as a result of participating in the community of practice. I emailed all community of practice faculty members and asked people to respond to my email if they felt as though they and/or their teaching had changed as a result of their participation in the community of practice. Of those who responded to my email, I selected four faculty members for interviews. Three are full- 
time employees of the college, and two instructors identify as male and two as female. The interviews were recorded and transcribed. As in my coding with artifacts and the focus group, I used descriptive coding except in the cases where the faculty developed their own terms to refer to key concepts of their work. In these cases, I used in vivo codes (Saldaña, 2013).

This research contributes to the body of research on reforms of developmental English education by providing a robust quantitative analysis. In addition to analyzing the impact of the intervention on student success in the English sequence, it compares this success to the developmental English program it replaces and the traditional collegelevel English course, which effectively serves as a benchmark for college-level success. In addition to the analysis of student rates of success at the course and sequence-level, this research determines the time required for sequence completion. This research will be among the first to provide information regarding the faculty experience implementing a developmental reform. The analysis of the impact of the community of practice on English 105 faculty will provide needed insight on the successful implementation of developmental English reform. 


\section{Chapter Four: Quantitative Findings Regarding Student Outcomes}

This study focuses on how structural changes in developmental education impact student success and faculty teaching. This chapter will address student success understood through quantitative research. The research question asks how structural changes affect rates of student success in a reform of the English developmental course sequence. This question evaluates the rates of success that students achieved in English 105. These rates of success are compared to rates achieved in the traditional developmental course sequence and the traditional college-level sequence. Data are disaggregated to determine if the intervention has any impact on equity. Sub-questions include:

a. What are rates of completion of English 105 with an A, B, or C among students who enroll in English 105?

b. What are rates of completion of English 110 with an A, B, or C among students who complete English 105?

c. What is the time to completion of English 110 with an A, B, or C among students who complete English 105?

For most student populations, English 105 produced higher rates of success in college level English and the English sequence than English 846. English 105 matriculated students through the English sequence more quickly than English 846 or English 100. English 105 was also effective in addressing equity issues in college-level 
English. To summarize, most students who enrolled in English 105 were more likely to complete the English sequence and do so in less time.

\section{Success in the First English Course}

Whether a student begins at the developmental level or at college level, success in the first English class is important. Success can reduce the time the student spends in the English sequence, and may influence whether or not the student completes the sequence. This research focuses on a comparison of English 105 to English 846, the class that English 105 replaces for nearly every student who was previously placed into developmental English. For English 105 to be effective, it must provide students with better outcomes than they would have achieved via English 846 . I have also provided comparisons of English 105 to English 100 to provide context for college-level achievement. English 100 is the first course in the traditional college-level English sequence, and levels of success in English 100 can serve as a benchmark for success in English 105.

Descriptive Analytics. In this study, rates of student success in English 105 surpass rates of student success in both English 846 and English 100. Table 9 shows that English 105 produces a rate of student success that is $1.23 \%$ higher than rates of success in English 846. At this slight margin, twenty more students would have passed English 846 if the two courses had equal rates of success. English 105 produces rates of student success that are 3.24\% higher than rates of success in English 100. Had English 100 
produced the same rate of success as English 105, there would have been 318 students who would have completed English 100 successfully. To determine the significance of the higher pass rates in English 105, I conducted $t$ tests.

Table 9

Success in first English class

First English class $\quad$ Rate of student success

English $846(\mathrm{~N}=4394) \quad 66.73 \%$

English $105(\mathrm{~N}=1595) \quad 67.96 \%$

English $100(\mathrm{~N}=9821) \quad 64.72 \%$

Note: Samples are all enrollments, including duplicated students.

Welsh $t$ test of the first English course. The $t$ test that is most beneficial to use in the comparisons of English 105 with English 846 and 100 is the Welsh unequal variances $t$ test. The Welsh $t$ test is well suited for this analysis because it accommodates for unequal sample size and is reliable when the two samples have unequal variances, as is the case with the data shown in Table 10 . The Welsh $t$ test measures the probability and significance of the differences in means.

Table 10

Average mean and sample size in first English class

\begin{tabular}{lcc}
\hline Course & $\bar{x}$ & $n$ \\
\hline English 846 & 0.642039 & 4194 \\
English 100 & 0.641624 & 9821 \\
English 105 & 0.682358 & 1595 \\
\hline
\end{tabular}


Shown in Table 11, this comparison of rates of success in English 105 and 100 does not meet the standard for significance. The results of this test indicate that by chance alone a difference of this magnitude would occur $11.23 \%$ of the time, which does not meet the $5 \%$ needed to reasonably disprove a chance occurrence. The $t$ test shows that

Table 11

English 105 vs 100 t test

\begin{tabular}{l|l|l|l|l}
\hline Test & $t$ & d.f. & $p$ & range \\
\hline Engl 105 vs 100 & -1.2147 & 2149.7 & 0.1123 & $($-inf, -0.0065$)$ \\
\hline
\end{tabular}

English 105 does not reliably produce rates of success that are higher than English 100 . However, for English 105 to produce rates of success that are similar to English 100, the traditional English class, means that English 105 attains the goal of producing collegelevel outcomes for students who would otherwise have enrolled in a developmental course.

English 105 reliably produces rates of success that are significantly higher than English 846. The results of the Welsh $t$ test shown in Table 12 calculate a $1.8 \%$ probability that the higher rates of success in English 105 occurred by chance alone.

Table 12

English 105 vs 846 t test

\begin{tabular}{l|l|l|l|l}
\hline Test & $t$ & d.f. & $p$ & range \\
\hline Engl 105 vs 846 & -2.2142 & 2590.2 & 0.01345 & (-inf, -0.0092) \\
\hline
\end{tabular}

These results indicate that English 105 is likely to consistently produce higher course success rates than English 846. On this initial measure, success in the first course, 
English 105 produces beneficial results. English 105 surpasses rates of success in English 846 and produces rates of success that are at least equal to English 100. While this difference in the rate of success between English 105 and 846 indicates that English 105 alone has promising outcomes for students, English 105 replaces two courses in the traditional sequence: English 846 followed by English 100. A true evaluation of the impact of English 105 would compare student success in English 105 to the success rate in English 100 of students who started in English 846. This evaluation is shown below in success in the first college-level course.

\section{Success in the First College-level English Course}

The previous analysis addressed success and failure in the first course. However, course failure is not the only factor contributing to attrition between developmental and college-level course completion. After Cloudline students successfully complete the developmental course, English 846, their next step is to enroll in and successfully complete the first college-level English class, English 100. Enrollment is a critical next

step. Research documents that even after successfully completing the developmental course, there are students who will not enroll in the college-level course (Bailey, 2009; Hern \& Snell, 2010; Rodriguez, Mejia, \& Johnson, 2016). This phenomenon, referred to as the leaky pipeline, (Henry \& Stahl, 2017) acknowledges that successful students drop out of developmental sequences. Table 13 confirms that this leaky pipeline phenomenon occurred at Cloudline College. 
Table 13

College English enrollment patterns of unduplicated students who begin in English 846

\begin{tabular}{llc}
\hline Enrollment pattern & $\mathrm{N}$ & \% of 846 population \\
\hline Passed English 846 \& passed English 100 & 1540 & $41.06 \%$ \\
Passed English 846 \& failed English 100 & 427 & $11.38 \%$ \\
Passed English 846 \& didn't enroll in English 100 & 809 & $21.57 \%$ \\
Failed English 846 & 974 & $25.97 \%$ \\
\hline Total students enrolled in English 846 & 3,750 & $99.98 \%$
\end{tabular}

The role of developmental English is to prepare students for college-level coursework. Table 13 shows that only $52 \%$ of English 846 students enrolled in English 100. While about half of students who begin in English 846 eventually progress to English 100, only $41 \%$ of 846 students ultimately pass English 100. Twenty percent of the English 846 students are ready for college-level English, but never enroll in the course. Twenty-five percent of the students who enroll in English 846 fail and never attempt the course again. The enrollment patterns show a lack of persistence among about half of English 846 students, regardless of whether they pass or fail the course. These results could indicate that a developmental placement alone is discouraging and sends the message that the student isn't college material (Bailey, 2009; Rodriguez et al., 2016) even when the student passes the course.

As discussed earlier in the chapter, the rates of first course success for all students range from $64-66 \%$ (Table 9). While this rate is still lower than desired, it is a rate that is consistent across the three classes. Table 14 highlights the impact of the leaky pipeline. The table shows successful completion of college-level English for all three starting 
points for English, developmental and college-level. Attrition further reduces the population of English 846 students who complete the college level. The effect of the leaky pipeline shows up as a success rate in the college-level course that is more than $20 \%$ lower among English 846 students than students who start at college-level.

Table 14

Success in first college-level English class

\begin{tabular}{lll}
\hline First English class & Rate of enrollment & Rate of student success \\
\hline English $846(\mathrm{~N}=4394)$ & $68.10 \%$ & $43.21 \%$ \\
English 105 $(\mathrm{N}=1595)$ & $100.00 \%$ & $67.96 \%$ \\
English 100 $(\mathrm{N}=9821)$ & $100.00 \%$ & $64.72 \%$
\end{tabular}

The benefit of removing the developmental course and accelerating students to the first college-level course, as English 105 does, is evident in the descriptive statistics as well as the analytic statistics.

Welsh $\mathbf{t}$ test of the first college-level course. English 105 has a high probability of consistently producing better rates of student success in college-level English than the combination of English 846 and 100. Table 15 shows that the Welsh t test calculates a p value well below the 0.05 that is required to demonstrate a significant difference. The evidence provided by the results of this t test offers

Table 15

Success in the first college-level course t test

\begin{tabular}{l|l|l|l|l}
\hline Test & $t$ & d.f. & $p$ & range \\
\hline Engl 105 vs 846 & -2.2142 & 2590.2 & 0.013 & $($-inf, -0.0093$)$ \\
\hline
\end{tabular}


compelling support for replacing English 846 with English 105. The another benefit of English 105 on student success is evident in the rate of success in the full college-level sequence.

\section{Success in the College-level English Sequence}

Completion of college-level English is a requirement for all students who are completing a Cloudline College degree. Most degree-seeking students also complete a second English class, English 110, in order to satisfy transfer requirements. Students who are required to complete this class include all who plan to transfer to a California public four-year university, some in-state private colleges and universities, and many outof-state public and private institutions. The course is so widely regarded as a requirement that transfer students who aren't required to take the course are still advised to. The units are transferrable and provide an option in the event that the student changes their transfer

plans. Because of the need of many students to successfully complete the English sequence, the impact of English 105 carries into English 110.

English 105 produces strong rates of success in the English sequence compared to English 846 and 100. Table 16 shows the rates of success in completion of the English sequence among students who start in English 846, 105, and 100. The rates of success that English 105 students achieve in English 110 is $1.44 \%$ lower than students who start with English 100. On the other hand, the rate of success achieved by English 105 
Table 16

Success in English sequence

First English class

English $846(\mathrm{~N}=4394)$

English $105(\mathrm{~N}=1595)$

English $100(\mathrm{~N}=9821)$

Rate of student success in English 110

$39.44 \%$

$46.79 \%$

$48.23 \%$

students is $7.35 \%$ higher than students who started in English 846. The strong sequence success that English 105 produces for students is confirmed in the $t$ test, as described below.

Welsh $\mathbf{t}$ test of the English sequence. Students in English 105 are more likely than students who begin in English 846 to successfully complete the English sequence. The $t$ test confirms that their success is not the result of chance alone. Table 17 shows that the $t$ test calculated the $p$ value of this rate of success as 0.004 .

Table 17

Success in the college-level sequence t test

\begin{tabular}{l|l|l|l|l}
\hline Test & $t$ & d.f. & $p$ & range \\
\hline Engl 105 vs 846 & -2.6387 & 577.14 & 0.004274 & (-inf, -0.0233$)$
\end{tabular}

This highly significant difference between the two course outcomes provides strong evidence of the effectiveness of accelerated English 105 in replacing the traditional developmental course, English 846. 


\section{Time to Complete the English Sequence}

Students who begin English enrolled in English 105 complete the English sequence in less time than students who start in English 846 and English 100. Data in Table 18 shows that most English 105 students complete the English sequence in two semesters, whereas students who begin in English 846 finish not in three semesters, as might be expected due to the longer sequence, but nearly four.

Table 18

Success in English sequence

\begin{tabular}{ll}
\hline First English class & Semesters to complete sequence \\
\hline English $846(\mathrm{~N}=3768)$ & 3.828 \\
English $105(\mathrm{~N}=513)$ & 2.198 \\
English $100(\mathrm{~N}=4736)$ & 2.590
\end{tabular}

Note: data is limited to a period of two years to ensure a similar window for each data set.

It is also interesting that the time to completion for English 105 students is even shorter than for English 100 students, indicating that the course is effective at promoting timely and successful English completion.

\section{English 105 and Equity}

Developmental education reform offers all students who are referred to developmental courses better outcomes. However, the disproportional impact of developmental education on African American, Latinx, students with low incomes, and students attending community colleges is well documented (Attewell, Lavin, Domina, \& 
Levey, 2006; T. Bailey, 2009; Perry et al., 2010). Developmental reform provides colleges with the tools to dismantle structures that have perpetuated institutional inequity based on race and income. This analysis indicates that English 105 advances equitable student outcomes in college-level English.

Student success disaggregated. English 105 produced higher rates of student success than English 846 among most student populations. Table 19 shows that Asian, Filipin@, and African American students as well as students who identify with more than one racial group, and those who not disclose their race or selected "other," all show improved outcomes in English 105 compared to English 846. Among these students, four groups had small increases in success ranging from $1.36 \%$ to $3.86 \%$ with an average among these four of an increase of $2.57 \%$. Outstanding increases in success

Table 19

Student success in English 846 and English 105 disaggregated by race

\begin{tabular}{l|l|l|l}
\hline & $\begin{array}{l}\text { English 846 } \\
(\mathrm{n}=4394)\end{array}$ & $\begin{array}{l}\text { English 105 } \\
(\mathrm{n}=1595)\end{array}$ & $\begin{array}{l}\text { Change in rate } \\
\text { of success }\end{array}$ \\
\hline Asian & $72.90 \%(\mathrm{n}=565)$ & $75.00 \%(\mathrm{n}=224)$ & +2.1 \\
\hline White & $68.45 \%(\mathrm{n}=466)$ & $67.29 \%(\mathrm{n}=159)$ & -1.16 \\
\hline Filipin@ & $70.23 \%(\mathrm{n}=1018)$ & $73.22 \%(\mathrm{n}=366)$ & +2.99 \\
\hline Latinx & $64.32 \%(\mathrm{n}=1068)$ & $60.39 \%(\mathrm{n}=409)$ & -3.93 \\
\hline Multi Races & $64.54 \%(\mathrm{n}=925)$ & $65.90 \%(\mathrm{n}=352)$ & +1.36 \\
\hline African American & $52.44 \%(\mathrm{n}=225)$ & $77.14 \%(\mathrm{n}=35)$ & +24.73 \\
\hline Other & $66.14 \%(\mathrm{n}=127)$ & $70.00 \%(\mathrm{n}=50)$ & +3.86
\end{tabular}

were achieved by African American students in English 105, who achieved the highest rates of success of any student population in a first English course. African American 
students increased their rate of success by $24.73 \%$. The increase in success rate could be attributed to English 105 and the transfer-level curriculum and pedagogy employed by faculty. Rates of success among Latinx students in English 105 was slightly higher than Latinx students in English 100 but lower by $3.93 \%$ than students in English 846.

Learning communities. Participation in a learning community may present a confounding variable in the comparison of rates of success among students in English 846 and English 105. Many African American students enrolled in English 846 taught by a single instructor as part of a learning community. English 105 was not taught as part of a learning community, because the long-time English faculty associated with the learning community was concerned that students would not succeed in an accelerated, transferlevel course. African American students in English 105, including students who typically would have enrolled in Umoja, demonstrated outstanding success at the transfer-level, completing the class with a variety of English faculty not teaching in the African American learning community.

Lower rates of English 105 success among the Latinx student population may also have been confounded by learning community enrollment. Students enrolled in Puente had the option to enroll in either English 846 or English 105. While this structure was intended to increase Puente student access to college-level coursework, it also had the impact of concentrating English 846 enrollments with one instructor and English 105 enrollments with another, which could have evidenced in this data as an instructor-level 
effect. As mentioned earlier, learning community data and instructor level data was not collected for this research. Further research could potentially explore the interaction of instructor level and learning community effects on success.

Rates of success in English 100 serve as a benchmark for rates of success in the first college-level course. As shown in Table 20, English 105 consistently produced rates Table 20 Student success in English 100 and English 105 disaggregated by race

\begin{tabular}{l|l|l|l}
\hline & $\begin{array}{l}\text { English 100 } \\
(\mathrm{n}=9821)\end{array}$ & $\begin{array}{l}\text { English 105 } \\
(\mathrm{n}=1595)\end{array}$ & $\begin{array}{l}\text { Change in rate of } \\
\text { success }\end{array}$ \\
\hline Asian & $72.00 \%(\mathrm{n}=1875)$ & $75 \%(\mathrm{n}=224)$ & +3.0 \\
\hline White & $68.27 \%(\mathrm{n}=1497)$ & $67.29 \%(\mathrm{n}=159)$ & -0.98 \\
\hline Filipin@ & $65.36 \%(\mathrm{n}=2073)$ & $73.22 \%(\mathrm{n}=366)$ & +7.86 \\
\hline Latinx & $60.01 \%(\mathrm{n}=1773)$ & $60.39 \%(409)$ & +0.38 \\
\hline Multi Races & $59.92 \%(\mathrm{n}=2056)$ & $65.90 \%(\mathrm{n}=352)$ & +5.98 \\
\hline African American & $59.62 \%(\mathrm{n}=265)$ & $77.14 \%(\mathrm{n}=35)$ & +24.73 \\
\hline Other & $62.06 \%(\mathrm{n}=282)$ & $70.00 \%(\mathrm{n}=50)$ & +7.94
\end{tabular}

of student success that exceeded the rates of success students achieved in English 100.

With the exception of white students, who demonstrated a $0.98 \%$ lower rate of success in English 105, all other student populations exceeded the rates of success demonstrated in English 100 . With increased rates of success ranging from $0.38 \%$ to $24.73 \%$, there is evidence that most English 105 student populations surpassed the benchmarks for college-level success established by the same populations in English 100.

Welsh $t$ test and equity in English 105 vs English 846. Among African American, Latinx, and Filipin@ students, English 105 reliably produces higher rates of success than English 846 in three critical comparisons. The Welsh $t$ test was used to 
determine if the outcomes achieved by students in English 105 could be attributed to chance alone. Due to small numbers of African American, Pacific Islanders, American Indians, and Alaskan Native students in the English 846 and 105 samples, these student populations were combined with Latinx, Filipin@, and mixed race students for the purposes of conducting the $t$ test. The tables will refer to this combined population as African American, Latinx, Filipin@. The gaps in success rates between Asian, white and unknown students and the combined populations in the African American, Latinx, Filipin@ group indicate that a comparison of these grouped populations will assess English 105 's impact on the equity gap.

Table 21

African American, Latinx, Filipin@ success in English courses t test

\begin{tabular}{l|l|l|l|l}
\hline Students enrolled in 105 vs 846 & $t$ & d.f. & $p$ & range \\
\hline Success in the first English course & -2.0983 & 1898.2 & 0.018 & (-inf, -0.0087) \\
\hline $\begin{array}{l}\text { Success in the first college-level } \\
\text { course }\end{array}$ & -2.1935 & 1768.4 & 0.0142 & (-inf, -0.0102) \\
\hline Success in the English sequence & -2.2193 & 415.92 & 0.0135 & (-inf, -0.0161)
\end{tabular}

The results shown in Table 21 show that among African American, Latinx, and and Filipin@ students, English 105 produces significantly higher rates of success than English 846 in three comparisons: the first English class, the first college-level course, and the full English sequence. The $t$ test calculates a $p$ value of less than 0.005 for each of the three comparisons. The results of the $t$ test in these three analyses indicate that English 105 is likely to consistently produce higher rates course success than English 846 
among African American, Latinx, and Filipin@ students. These results are confirmed in a regression analysis.

Conditional inference tree definition. Levshina (2015) describes conditional inference trees as non-parametric tree-structure models of regression and classification that can serve as an alternative to multiple regression. They are especially useful in the presence of many high-order interactions and in situations when the sample size is small, but the number of predictors is large as is the case with the English 105 data. Conditional inference trees use binary recursive partitioning to attribute the effect of independent variables on the response variable. As in the $t$ test, student populations were grouped to create larger sample sizes and to measure the impact of English 105 on the equity gap. African American, Pacific Islanders, American Indians, and Alaskan Native students were combined with Latinx, Filipin@, and mixed race students. Asian students were grouped with white students and students whose race is marked as unknown.

Conditional inference test results. The conditional inference test shows that English 105 is strongly associated with student success among all genders and races of students. Figure A shows the results of the conditional inference test. The conditional Figure A

Conditional reference test first college-level course 


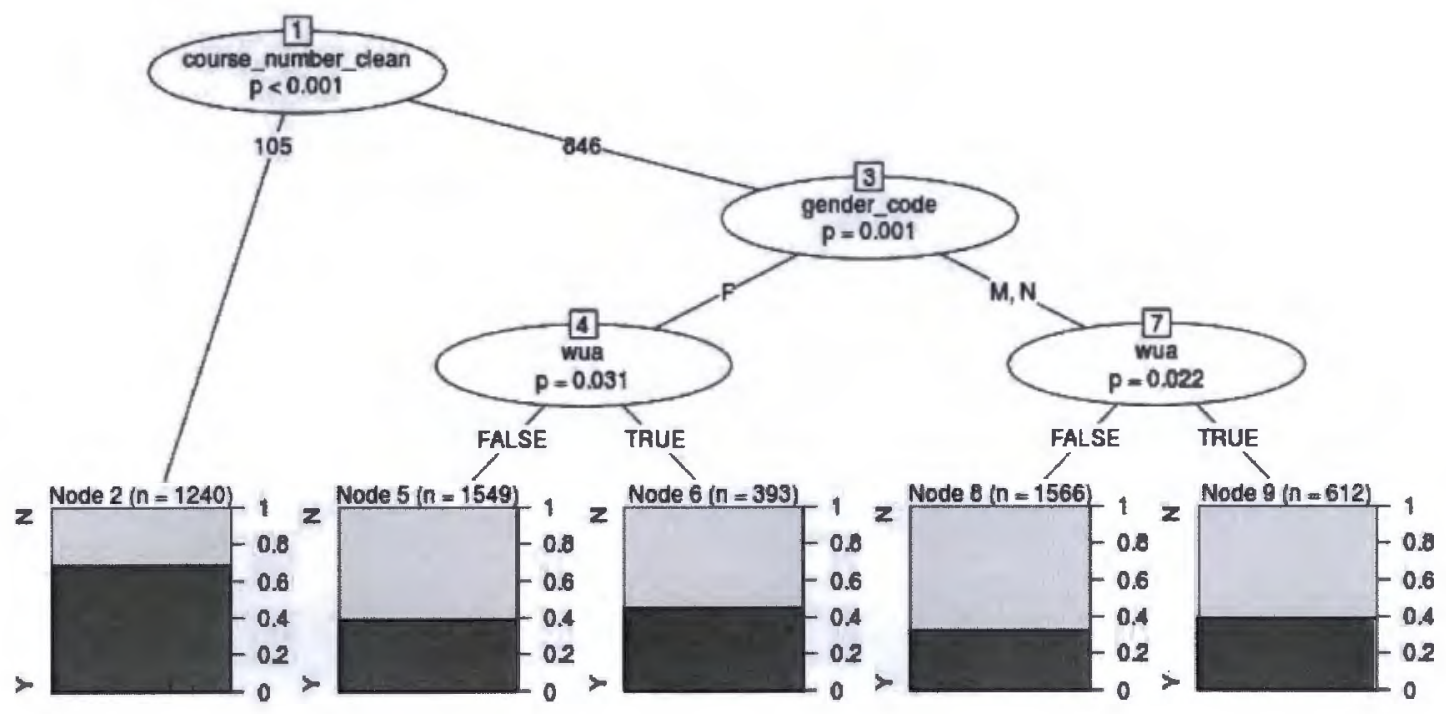

reference test shows that of the independent variables (course number, gender, and race) course number is the variable most often associated with student success in the collegelevel English sequence. English 105 has a stronger association with success than English 846. Node 1 shows that there is a $0.1 \%$ probability that chance alone led to the association of English 105 and student success.

After course number, the variable that is most often associated with success is gender. Node 3 shows that female students are more likely than male and students of unknown gender to be successful in English 846 . There is a $0.1 \%$ probability that chance alone led to the association of gender and student success.

Within the English 846 population, after gender, race is associated with student success. Among the male, female, and unknown genders, Nodes 4 and 7 indicate that 
Asian, white, and students whose race is unknown are shown to achieve success slightly more often than African American, Latinx, Filipin@, mixed race, Pacific Islanders, American Indians, and Alaskan Native students.

Not only does Node 1 show that English 105 is the variable most often associated with success among students in the first college-level English course, there are no patterns of success associated with gender or race. The regression analysis indicates that students of one gender are equally likely to be successful as students of other genders. Likewise, Asian, white, and students of unknown race are as likely to be successful in English 105 are African American, Latinx, Filipin@, mixed race, Pacific Islanders, American Indians, and Alaskan Native students. This regression analysis does not detect a pattern of success in English 105 associated with race or gender.

Overall, English 105 produces consistent rates of success among students. Node 2 shows that all students enrolled in English 105 have approximately a $70 \%$ chance of success in the class. This analysis does not detect a difference in the likelihood of success in English 105 based on the student's gender or race. Students in English 846 have lower odds of achieving success in college-level English, ranging from slightly below to slight above $40 \%$. Nodes $5,6,8$, and 9 reiterate the finding in the regression analysis that gender and race are associated with different likelihoods of course success among students enrolled in English 846. 


\section{Summary}

The results of the research offer compelling evidence for replacing English 846 with English 105. The research and analysis show that English 105 produces higher rates of success in college level English and the English sequence than English 846. While descriptive analytics show slightly lower rates of success among the Latinx population in the first course taken, the impact of the leaky pipeline offsets this gain. Further, the gap in success rates that are demonstrated in English 846 are not detected in the analysis of English 105, suggesting that English 105 is effective in addressing equity issues in college-level English. Not only does English 105 help more students complete the college-level sequence successfully, it does so in less time. English 105 shows great potential for removing barriers to successful completion of college-level English. With the implementation of English 105, African American, Latinx, Filipin@, mixed race, American Indian, Alaska Native and Pacific Islander student populations have equitable outcomes in college English as an option. 


\section{Chapter 5: Qualitative Findings}

This study focuses on how structural changes in developmental education impact student success and faculty teaching. The analysis provided in this chapter addresses the faculty experience in the reform of developmental English. The first question asks what challenges faculty of college-level English face as a result of structural changes in developmental English. This question provides an important frame for the second question, which asks how participation in a community of practice impacts faculty responses to structural changes in developmental English. Together these two questions seek to research the experience of the faculty members who implemented English 105. The chapter begins with findings from the first question, and then delves into the community of practice findings which produced rich and robust results.

Instructors reject the notion that teaching the heterogeneous mix of students found in English 105 is different from teaching any other heterogeneous mix of students. Faculty characterized the challenges of the structural change as familiar, adding that the potential for a range of students in English 105 was greater than in other English classes. Their most important resource to address a variety of students was time in class and with individual students. To support faculty implementing the change, the community of practice provided a professional community in which instructional resources, validation, and the practice of intentionality could produce the paradigm shift necessary to 
successfully implement the structural change. The community of practice was effective in providing a supportive network as faculty implemented change.

\section{Challenges of Implementing Structural Change}

When Cloudline College implemented English 105, students who would have begun college in a five-unit developmental English course, enrolled instead in a five-unit college-level course. English 105 committed faculty and students to achieve collegelevel outcomes in the same instructional time that they had previously pursued developmental outcomes. In fact, the reform entailed achieving college-level outcomes in one less semester and 54 fewer instructional hours than the traditional model. However, this wasn't the perspective that English faculty took when they implemented the structural reform. When English 105 faculty abandoned developmental English as a default placement for half of the incoming class, they also abandoned the belief that students needed the class to be successful. Rather, faculty engaged in teaching English 105 with the belief that students belonged in either the traditional three-unit English course or the reformed, five-unit English 105.

A heterogeneous group of students. As a result of removing the developmental prerequisite, the student population in English 105 had a wide range of experience with critical thinking, analytical reading, and composition. Increased variety in student preparedness was the greatest challenge faculty faced in implementing the structural change. Adrian, a part-time instructor experienced in teaching creative writing and 
literature, taught English 105 in his first semester at Cloudline College. He observed that "there was a broad spectrum of students in the room" including students who already knew how to structure essays and were experimenting with language (Letter to future 105 faculty, December 2016). He described the most challenging as a few students who "do not know how an essay works and have grammar and sentence structure issues that prevent any ideas from getting through," (Letter to future 105 faculty, December 2016). Although he stated that the great majority of students fell between these two extremes, both new and experienced faculty found this range of student preparedness challenging to address effectively.

A familiar challenge. Faculty regarded the range in preparedness among English 105 students as challenging; however, it was also familiar. Instructors teaching English 846 argued in favor of implementing English 105 by stating that English 846 routinely had students who could have started at English 105. When discussing the primary challenge of teaching English 105, Monica, a new part-time instructor, stated I think we all know since placement tests are not maybe the most reliable for grouping students by their level of ability, we always deal with this same problem, which is essentially that students come in to the classroom at varying levels of readiness for the material. (Interview, October 20, 2017) Monica points out that placement tests do not result in classes of students who begin a class with the same strengths and same needs. However, this mix within a class can also 
result even when entering students have completed the same prerequisite. Satori, a fulltime instructor who teaches ESL and English, also observed a mix of students in her traditional English 100. Even though she had taught the same group of students in the prerequisite ESL course, and students had satisfied the prerequisite, a range of student preparedness persisted. Some students "came in really strong to the class" and there were others who struggled (Interview, October 24, 2017). Teaching a spectrum of student preparedness in a single class is a challenge in English 105 and other composition courses as well.

The real challenge: time. When faculty members describe heterogeneous groups of students, they are quick to point out that the range of preparedness isn't what is daunting. Monica explains that "what really poses challenges is a lack of time and ability to be able to one-on-one sit down and address each student's unique needs" (Interview October 20,2017). Monica will use this time to listen to students to understand their needs, or to spend time with students to address those needs. Additional time means that instruction can be differentiated, or adjusted to build community or provide more hands on application. Faced with the range of student preparedness, faculty name time as the most important resource to address a variety of student needs. Instructors' foremost concern is having sufficient instructional time to address the range of students in their class. 
Some of the most powerful memories related to instructional time surface when instructors remember not having enough time. Satori recalls having insufficient instructional time when she taught the traditional English 100.

Some of the students were fine but, you know, they came in really strong to the class. You know, they had the level but it was really tough for the students who just needed extra time, who struggled. I feel bad because I think that if [it had been a] 105 class, I think I would have had a higher level of students passing but I think because there was not enough support, there's - I lost some, just to be honest, and I felt very frustrated by that. I felt that there was not enough time to take them to computer lab. There was not enough time where I could work with them one-on-one, I mean besides office hours. But during class time, my style of teaching is to do a lot of scaffolding and lot of support, and I felt like the three hours a week, you know, could barely even touch the surface. I almost felt like, 'Hi, everybody. Here's your essay and have fun. Do it on your own.' And that's just not how I like being a teacher. And to be honest, it's probably the worst class I've ever taught at Cloudline. All the other classes I felt like, 'This is great. You know, I can support the students. The students are, you know, getting something out of that.' But the 100, I just - I didn't feel successful as a teacher.

Sufficient time. By contrast, when Satori teaches English 105, she has the instructional time to provide sufficient scaffolding so that all students are supported and 
progressing. The additional time allows Satori to introduce students to instructional resources like the computer lab and the writing center, and it allows her to work with students one-on-one during the class.

Not only does the instructional time benefit students, it also benefits instructors. In the same way that students need adequate time to achieve learning outcomes, instructors need adequate instructional time to support the development of those outcomes. Insufficient time produces conflicts with instructors' professional and personal values. At an essential level, insufficient instructional time produces a conflict in how instructors view themselves as teachers. Without enough time, they are forced to make instructional compromises that are inconsistent with their images of themselves as teachers. In contrast, English 105 provides sufficient time for instructors to serve their students in a manner consistent with their values.

\section{Summary on the challenges of implementing structural change}

With the removal of English 846, the students who enter English 105 demonstrate a wide range of preparedness for the class. The wide range of student preparation is both concerning and familiar. Faculty have taught similar ranges of students in the past in classes that provide less instructional time. Students who would have been classified as developmental take three fewer units of English as a result of the structural change. Despite this, instructors perceive of English 105 as providing additional and adequate instructional time because the course has two more units that the traditional college-level 
course, English 100. The additional two units in the college-level course provide faculty the necessary instructional time to adjust instruction to serve the range of English 105 students. Faculty found it straightforward to identify the challenge of teaching English 105 , and not nearly as important, interesting, or complex as talking about their participation in the community of practice. Consequently, the community of practice findings comprise the remainder of this chapter and reflect the volume and complexity of their experiences with community of practice.

\section{Faculty Outcomes from Participation in Community of Practice}

This research asks how participation in a community of practice impacts faculty responses to structural changes in developmental English. A critical shift in thinking about developmental education occurred among the Cloudline College English faculty when they decided that nearly all students were prepared to be successful in college-level English. The community of practice facilitated another shift when faculty changed their

pedagogy in order to ensure student success. The community of practice informs faculty responses to the range of students they will teach in English 105 by building a professional community that provides connection, resources, jdeas, and support.

The remainder of this chapter will analyze English 105 faculty experiences within the community of practice. Faculty discuss isolation, connection, validation, and changing instructional practice. Changing from inherited models of instruction, instructors changed practice in three ways, including perfecting, adapting, and 
transforming practice. The chapter concludes with a discussion of instructors who transformed themselves instructionally by using intentionality. Adopted in the community of practice, intentionality initiated a process of actualization among some participants. These instructors rejected the idea that they had changed as a result of an external influence. Rather, they described becoming the instructor they had been holding within themselves. As mentioned previously, community of practice has rich potential for professional development. This chapter attempts to provide a detailed analysis of that potential as evidenced by the Cloudline College English faculty.

Inherited pedagogy and policies. Before faculty engaged in the community of practice, they reported that they had not given much thought to the origin of their ideas about teaching. Rather they adopted practices and policies that were informed by their experience as students and understanding of college policies. Speaking of her own ideas about teaching, Monica mused that "I think a lot of times that those ideas get inherited through ... I don't know if it's reading or just our experiences of watching other professors" (Interview October 20, 2017). Whatever the source of her idea of teaching, Monica described a traditional teacher. She says that I inherited this sort of idea that as the teacher you needed to come in and be the expert and sort of give that expertise to your students and that you should stick to a schedule and you should get through what you need to in a day and sort of that's the right way to teach a class. (Interview October 20, 2017) 
Other colleagues of Monica's credited college policies with informing their perception of the role of the teacher. During the focus group, Destina and Leah discussed the rule-oriented nature of the traditional teacher. Destina mentioned "the handbook of handbooks" which suggested that there are general rules that traditional teachers follow, but that there is also a higher order set of guidelines that are non-negotiable. The rule regarding three absences provoked Leah to pronounce the rule: "You missed class (twice). You miss one more class, and you're done forever." (Focus Group, April 15, 2017). The group widely understood the role of the teacher as one who knew and enforced this rule.

Finally, English faculty learn their role as rule followers and rule enforcers through communication with their dean and senior faculty. As new faculty come into their role as teacher, they rely on leadership to help them understand and conduct their role. Sometimes the law is laid down as an absolute. Bob concurred with his colleagues, adding, "Yeah, [the rule] was told to me, just like it's told to students" (Focus Group, April 15, 2017). Bob, Leah, and Destina's conversation about the attendance policy was particularly energetic because they had just learned that what they thought was a hard and fast college policy was actually a guideline that allowed for faculty discretion. Some felt as though by enforcing a policy they had taught in a manner that was incompatible with their values and pedagogy. Leah stated that she sent "conflicting messages" by sharing 
her power in the classroom and enforcing this guideline like "she's the boss," and makes all the rules (Focus Group, April 15, 2017).

Not all faculty conform to traditional pedagogy and policies. In the college's first phase of acceleration, when a course two levels below transfer ceased to be offered, faculty developed new curriculum to serve students effectively. There was not a community of practice, and faculty did not necessarily disclose their practices to their peers. This departure from traditional English instruction is something that some faculty were reluctant to fully discuss with each other before new practices were recognized and validated by the community of practice. Carl said that he didn't discuss his practices with his peers out of concern that he would be characterized as lacking rigor. His concern was warranted. One of his peers resisted non-traditional pedagogy like his because she wanted her "classroom to seem like 'college' (Letter to future 105 faculty, December 2016). It is no surprise then that some faculty, like Monica, described their adaptations as "a dirty secret" (Interview October 20, 2017). Without the contact and support colleagues in a community of practice, faculty may believe that they have to keep their innovations to themselves.

Instructional isolation. Many faculty, particularly part-time faculty, describe their work as lonely. Leah, a part-time instructor, observed that it is ironic to work in a room full of [students] and still feel lonely (Focus Group, April 15, 2017). The loneliness she describes is instructional isolation. Part-time faculty do not often have extended 
interaction with part-time or full-time peers. Sarah, a long-time part-time instructor wrote that the community of practice provided "focused attention and support with teaching-so rare in the everyday, glamorous life of an adjunct" (Letter to future 105 faculty, December 2016). However, with the exception of the tenure process and evaluation, full-time faculty are not more likely than part-time faculty to discuss their teaching in a focused and ongoing matter. Loneliness and isolation were all addressed when faculty became part of the community.

Connection within the community of practice. The community of practice not only brought otherwise isolated people into contact with each other, it brought part-time faculty and full-time faculty into peer relationships. It provided space and opportunity for all faculty to focus on teaching with an intellectual seriousness that participants compared to graduate school. Even faculty who Amy, a part-time instructor who has been teaching for seven years, wrote that the community of practice had given her "an appreciation for collaboration" although she is "used to working independently" (Letter to future 105 faculty, May 2017). Community not only served as a resource for knowledge and resources, it provided company and comfort in work that can lead to fear and doubt.

Faculty teaching in English 105 also reported stress that came in part from high self-expectations that they feared they wouldn't meet, especially as they were teaching a 
new course to students who previously would have been in developmental courses. Fulltime ESL instructor, Ellie wrote

I will admit that I was intimidated about teaching ENGL 105. This is not to say that I didn't want to seize the opportunity; it's just I was equally scared and excited. Sharing course ideas, example assignments, essay prompts, classroom management pointers, ideas about affective domain, and just talking with other fellow ENGL instructors increased my confidence. (Letter to future 105 faculty, May 2017)

For Ellie, part of her stress was caused by working outside of her primary area of expertise, but her stress was shared by others. In fact, many of the faculty members found in the cohort someone who was in their corner.

First year, part-time faculty member Destina conveyed her sense that her community of practice cohort got her through a challenging semester. In the quote below, Destina was speaking to her community of practice cohort and facilitator:

Destina: I just wanted all of you to know how fortunate I feel, that, uh... Being it-it being my first year that, you know, so many beautiful people have-- have-- kind of, like, uhm... helped foster the teacher that I want to become. Uhm... And not a lot of people have that.

Facilitator: [eyebrows up, nodding] Yeah. 
Destina: Especially in their first year. So I feel very fortunate... uhm, to be at Cloudline to know each and every one of you, and to see how much you all are trying. Uhm... and to see how tired and thoughtful you are.

\section{[Laughter]}

Destina: It helps to know that, like, yeah. Yeah. uhm... I could not do this without help, for sure.

[Chuckles]

Facilitator: Like I said, this is our last meeting, but we're always here for you, right? (Focus Group, April 15, 2017)

Destina's challenging semester was one that she shared with her community of practice cohort. When Destina was less successful than she hoped, when her students responded in ways she hadn't anticipated, when she tried earnestly to align her practice with principles of the English 105 community but wasn't always successful, her peers in the community of practice supported her. Destina was correct that the community of practice was a resource and community that many others do not have. Teaching in a different year, she might not have had the community of practice to lean on for support and to draw on for learning. 
New pedagogy. To ensure students' academic success, faculty adapted their curriculum and pedagogy. Many of the faculty arrived at necessary curricular changes prior to teaching English 105 when they were teaching traditional developmental courses. Experienced full-time faculty member Carl, describes devoting time, as much as the first two weeks of the semester, to developing community, belonging, knowledge of the campus, and a college-going identity among his students. Another experienced instructor, Bob, also incorporated this approach. As a result of the community he and the students developed, "students actively reach[ed] out to their absent peers, providing support to each other inside and outside of the classroom and collaborate to develop stronger reading and writing" (Letter to future 105 faculty, May 2017). As they described it, instructors' early efforts to build community resulted in peer support and persistence later in the semester when the course becomes more challenging.

Faculty practiced growth mindset. Critical concepts of the English 105 affective domain curriculum came from Dweck (2008). The faculty used texts, develop activities, design assignments, and even played music and videos to challenge students to abandon fixed mindsets and engage in growth mindsets. Faculty members teaching in English 105 reminded themselves that growth mindsets are good for them too. In letters to each other, they encouraged each other to "model learning from failure, be honest, and be kind to yourself" (Letter to future 105 faculty, May 2017). Another instructor explicitly reminded her peers to "model growth mindset for the students" by admitting 
mistakes and accepting it when we mess up. In part, this mindset helped to mitigate the sense of failure teachers felt when students did not hand in work, or if they did, did not demonstrate learning outcomes. Or worse.

When circumstances in students' lives interrupted their progress at school, faculty reframed the loss within a growth mindset on the student's behalf. Experienced part-time instructor, Leah provided an example of a student whose mother had cancer:

....and she missed, like, three or four weeks. I emailed and emailed. And then, she showed up for the library tutorials. So afterward, we talked, and I was just, like, you know... "How you doin'? What's goin' on?" You know, she's constantly crying. And she was putting so, so, so much pressure on herself with this idea that if she didn't finish, she had just blown it, and she was a failure, and it was all so bad.

And I was just like saying, "Uhm... Sometimes, this is not the right semester. Like, I will... I'll be honored if, I would love to have you back. You know, like, just take care of yourself." And she was just, like, crying. And she came back in the spring. She's in my class now, and she later sort of spoke up in class and... to-to motivate others to stay in that way. (Focus Group, April 15, 2017)

Dweck's growth mindset allows for "yet". Rather than concluding that a student has failed, Dweck (2008) asserted that the student has "not yet" me the goal. Faculty who 
can reframe grades of $\mathrm{F}$ on papers as "not yet" are also able to reframe unavoidable life circumstances that students encounter, which helps the student still see themselves as students and return in subsequent semesters. Leah's story was echoed by several instructors who had students return to their classes or college in general, often after devastating circumstances.

In addition to growth mindset, community of practice faculty framed the act of teaching as experimentation, which also offered a different frame on failure. In a letter to future 105 teachers, Amy wrote:

My best advice to you is to embrace experimentation.... My experiments this semester helped me find several new in-class activities that helped keep my students engaged. Remember though, that some experiments are successful . . . and some are not. It is okay to try something new and fail. In this vein, remember that you are learning — and so discussions that you might have your class about developing a growth mindset also apply to you. If I had a bad day with my 105 students, I tried to frame it as part of my own learning experience, and I would soothe the wound, as it were, by revising my lesson plan for the next semester. (Letter to future 105 faculty, May 2017)

Amy's encouragement to others that they experiment addressed the fear of failure that some faculty have, a fear of having a lesson not go well, a fear of embarrassment in front of their students, and a fear of letting students down. One 
instructor explained that her reluctance to engage in the English 105 was due to not wanting to change lessons that she had perfected by teaching them for many years. Embracing experimentation allows faculty to acknowledge the uncertainty that is already present in the act of teaching and reframes how the instructor engages that complexity.

Teaching practice. In a community of practice, individuals come together to improve practice by expanding knowledge and understanding and enhancing expertise. This common focus on practice that was evident in much of the documentation that I researched for this study. Faculty found great value in the opportunity to learn from their peers ways that they had been successful in their classes. While all faculty wanted to improve practice, how faculty perceived of the necessary changes to practice varied significantly.

Perfecting practice. One pair of instructors used the Community of practice as an opportunity to develop in detail a new curriculum in total for the 105 course. The two chose the same texts, developed the same syllabus, units, and assignments, and wrote a scaffolded lesson plan for each day. They taught the materials, and debriefed throughout the semester, making changes to their lessons and future plans based on their shared experiences. The two developed very useful plans that were thoroughly considered and vetted. 
Adapting practice. Karp \& Bork (2014) found that college success is at least in part predicated on students having a sense of comfort and belonging in college. With that in mind, many 105 instructors found ways to adapt practice to provide a coherent transition for students from their lives outside of the classroom into college. Adaptations included scaffolding, time for assignments, an increased awareness of instructional difficulty, and non-graded assignments. Faculty experimented with decentralizing the role of the teaching and becoming more flexible.

Faculty also cite changes to policies, mindfulness of the affective domain, and specificity in directions as ways that they are adapting to student needs. For example, a key principle of acceleration pedagogy is transitioning from frontloading remedial concepts to providing them just in time. Traditional remediation devotes time early in the semester to teach basic grammatical concepts. Accelerated pedagogy teaches these grammatical concepts later when students are finalizing drafts of papers. This delay to teach a concept when the student needs to use the concept is called Just in Time instruction.

Cloudline College English faculty adopted the frontloading concept from a negative connotation to a positive. They adopted the term to express being intentional about outcomes that they wanted to develop early in the semester. They described transitioning from a focus on rules to relationships and used relationships to express and uphold expectations. Some instructors spoke of "frontloading compassion" as a way to 
show students that there was a safety net in place long before they'd need it. At the end of the community of practice, Amy wrote that

It was new for me to explicitly focus on my students' emotions and psychological states, and I have to say it made a huge difference. As teachers we do this intuitively, but making it an explicit part of the course allowed me to frame my lesson and my tone appropriately each day....Thinking of each student's attitude and self-efficacy was also super helpful when I was grading. Even when I had a critique to impart, I tried to think about how I could present it in the most positive light, with an eye toward a hopeful future. (Letter to future 105 teachers, May 2017).

English faculty have found that creating a community and being personal and compassionate benefits students and promotes learning. The community of practice develops instructors' contextual awareness of student culture and helps them adjust to student culture in order to help students adjust to college.

Transforming practice. When asked about how the community of practice impacted them, some faculty acknowledged that they learned new strategies and techniques, but that more importantly, the community of practice transformed their thinking. For some, the transformation is about their new understanding of what they are teaching and what students are learning. For example, Sartori writes "More important than 'Can these students write a clear thesis statement? is 'Can they pick themselves up 
after a failure' and 'Do they understand that by putting effort into what they do, that they can improve?' (Letter to future 105 faculty, May 2017). Developing outcomes for the affective domain, and intentionally addressing it throughout the semester brought awareness to practices that were unintentionally making faculty gatekeepers, when their intentions were quite different.

Faculty provide multiple examples of ways that they have transformed their teaching. Ryan, a full-time faculty member provides this example of his use of language: I took a long look at how I deal with students day to day, how I come across to students, what my syllabus or class 'rules' and even my assignments convey to my students, about me and about my class. . I've learned to change some of the language in my syllabus and assignments so that the language isn't sending the wrong message and isn't, what I can only describe as threatening or warning. For example, students cannot do this, or students must do this. (Letter to future English 105 teachers, May 2017).

Ryan contributes this level of awareness to his participation in the community of practice, and conversations that his cohort had about hope and compassion. The cohort developed an awareness that policies and practices could thwart student hope and or could create possibilities for students when they might otherwise assume that hope is lost. Faculty report that leading with, or frontloading, high expectations and compassion is a means of providing access to the course and attainment of outcomes. 
Transforming themselves. As faculty wrote about how their teaching practice changed, they also described how they have changed. They do not describe themselves as having changed, but rather they describe themselves as having become. Amy writes the community of practice has pushed me closer to becoming the kind of teacher that I've always had inside me. The principles and practices of acceleration just feel right to me, and I love that the community of practice has given me permission to focus on being a teacher who is fun, kind, and caring — with high standards. (Letter to future 105 faculty, May 2017).

In this passage, Amy underscores the importance of having the community of practice to provide the practical resources she needs as an instructor. Additionally, she references the power of a community of peers who share a set of practices and beliefs. The community of practice validated changes Amy was making and gave her confidence to continue to change in alignment with her values.

Other faculty members echo the sense that the community of practice validates ideas or feelings that they held about teaching. Destina said the community of practice "allowed/fostered the teacher [she wished] to become" (Focus Group, May 2017). Monica states that the community of practice "allowed me to embrace some of the things that I had felt about teaching" (Interview, October 20, 2017). Although these instructors held an idea or the feeling of a new teacher within them, this idea or feeling was actualized only after their participation in the community of practice. The resources, the 
support, a practice of intentionality modeled within the community of practice provided the context necessary for instructors to change their practices to align with their higher ideals, or actualize.

Not all community of practice participants experience this level of actualization or transformation. Faculty must be open to the experience and "engage," a word several participants use, in the community, and the process. Ryan, the faculty member who described his intentional use of language, wrote about his intentionality about his teaching practice. He quotes Kabat-Zinn (1994) when he described the attention he had learned to pay to his teaching, his students, and his classroom. Ryan said he was "paying attention in a particular way, on purpose, in the present moment, and nonjudgmentally" (Letter to future 105 instructors, May 2017). For Ryan, what Kabat-Zinn (1994) defines as mindfulness was as important in his transformation as acceleration and compassion, and it allowed him to transform his teaching for his students.

Intentionality. Intentionality or mindfulness played a role in the actualization that Monica described as part of her community of practice experience. During our interview, Monica said that the community of practice allowed her to embrace things that she already felt about teaching. She was clear that she had not learned these things in teacher training, professional development, or by observing models. I asked her more about that.

Interviewer: What was present with you before the community of practice that got confirmed or acknowledged or acquired as an experience of going through the 
community of practice? It's not like there were something that's-- it's not foreign it was already there.

Monica: I think a huge part of that is the process of metacognition that I know that's something we're always teaching our students, but something that the community of practice does is ask you to pull yourself out of the physicality of being in the classroom and to think about, to theorize, to really put mental energy on why you are doing things the way you do them. And I don't think that-- I mean you could call it metacognition, you can call mindfulness, I think that there's lots different sort of terms for that kind of action, but refocusing your attention on intention and making sure that your intentions are matching your outcomes. I don't think people get a lot of opportunity to do that in any aspect of their lives and the fact that the community of practice frames that as productive work and as necessary work has changed the way that--even now that I'm not in the community of practice--that I'm looking at how my classes go and how I should change them semester by semester, even week by week. (Interview, October 20, 2017)

Monica credits the practice of intentionality with transforming her teaching. The practice that she learned in the community of practice urged her to ask herself what she intended as an outcome, what she was doing to achieve it, and what the results told her. As a result of observing others in that reflective practice, and Monica learned a way to change 
her present teaching. Monica concluded, saying "So, I guess, for me it was getting to have everybody do the work of looking at what they're already doing, looking at what they already know, what are their inherited ideas and then asking ourselves, "Okay, are those working? Does the data show that that's not true or that it is true?" (Interview, October 20,2017. As a result of engaging herself in that practice the community of practice equipped Monica to change her teaching now and as an ongoing process.

Summary. Community of practice has great potential to impact faculty knowledge and practical expertise in addition to bringing a greater sense of professional connection, belonging and satisfaction. The impact of the community of practice on individual faculty members is influenced by the degree to which individuals are open to or are seeking to change. The community of practice invites all participants to develop intentionality by being aware of all aspects of their teaching practice. As faculty increase their awareness of their contributions to the learning environment, another aspect of intentionality involves evaluating their impact on the learning environment, to understand how what they do as instructors contributes to their desired instructional outcomes. For faculty who were actively pursuing learning, the impact of the community of practice was transformation of their teaching and themselves. These participants consciously engaged in the experience and used the word "embrace" to encourage others in future cohorts to engage fully in the community. The community of practice can help faculty become a 
more actualized version of themselves if they engage in the community and adopt a selfreflective teaching practice.

Perin's (2002) premise that community colleges cannot increase access and maintain standards is being tested at Cloudline College and other colleges in the state where faculty and administrators are determined to serve student equitably. While the structural change of removing one level of developmental classes along significantly changes college-level completion, equipping faculty with the resources to ensure students' success at the college-level can produce even more change. Communities of practice are a promising means of ensuring that student outcomes and teaching and learning are transformed. 


\section{Chapter Six: Implications and Recommendations}

This research concludes that English 105 improved student success in collegelevel English and that participation in the community of practice supported faculty professional development. In this chapter I begin with a summary of those findings. My leadership philosophy and my thoughts on equity informed this work, and for that reason, I will reflect on the leadership that I believe is necessary to support institutional change and equity. I reflect on beliefs that are core to my leadership philosophy, and connect them to the work that took place at Cloudline College. I will conclude with suggestions for the implementation of accelerated English programs, with a focus on the implementation of $\mathrm{AB} 705$ in Califormia.

The findings of this research conclude that students enrolled in English 105 are more likely to complete the first and second college English class. Furthermore, students in English 105 complete the English sequence in less time than students who enroll in developmental English or the traditional college-level course. Disaggregated racial and ethnic data shows that all subgroups demonstrated higher rates of success in completing college-level English when they started with English 105 compared to the developmental course. While more data is needed to reduce the impact of learning communities and single instructor effects, English 105 had a positive impact on students' success and time to completion. 
Findings related to the faculty experience show that instructors needed additional instructional time in order to support the mix of students who enroll in English 105. Faculty responded to the range of student needs by using additional instructional time to work with students one-on-one, increase scaffolding, and to replace traditional developmental pedagogy with non-traditional pedagogies that created community among learners who were advancing to college-level outcomes. This pedagogical shift was made possible by faculty participation in a community of practice that brought innovation into the mainstream and validated practices that were regarded by traditionalists as lacking rigor or not suitable for college. As community of practice participants practiced intentionality, they began to transform their teaching and themselves. Supported by their own openness and desire to learn, faculty described the process of change not as a response to external forces but as an opportunity to become the teacher they had inside them.

\section{Reflections on Leadership and Change}

As the dean supporting this project, I had an opportunity to put my leadership philosophy into action. Faculty are capable of leading more institutional change than they are allowed to in most community colleges. I have observed vision, insight, and leadership potential among faculty in every institution I have worked in. Top-down administrators tend to limit faculty leadership, and overworked administrators may not have the bandwidth to mentor faculty leadership. When I began my work with Cloudline 
College faculty, I observed that administration was only partly responsible for limited faculty leadership. Faculty members were reluctant to envision themselves as leaders, and they did not regard the classroom as an important site of leadership and system-wide change. Some faculty believed that leaders had values and objectives that conflicted with those that informed their work in the classroom. My leadership philosophy is founded on my belief that faculty play crucial roles in leading institutional change.

Faculty should be partners in initiating, planning, and implementing institutional change. Faculty and administration should be aligned in our commitment to serve students, improve outcomes, and ensure that we are removing biased remnants of a system that has yet to serve students equitably. Deans need to work with faculty to design student-centered change that works in student lives and in the classroom and still meshes within aspects of the system that are slow or difficult to change.

Implementing this leadership philosophy required that I create space for faculty to begin to make change, even prior to initiating the college's work on acceleration. It meant listening to faculty ideas, providing a space and time for them to collaborate with each other, and encouraging them to think projects through from implementation to evaluation. I spent time brainstorming with faculty, asking questions, and sharing insights in ways that I hoped would lead faculty to make their own discoveries about the work they were doing. Space, time, and encouragement helped faculty build their capacity to lead change and expand their awareness of themselves as leaders. 
I scaffolded faculty leadership development by creating or supporting incrementally larger and more complex leadership opportunities for them to pursue. Rather than hand picking faculty for opportunities, I advocated for transparent opportunities for faculty to apply for leadership positions. I asked faculty leaders to have a practice of mentoring three faculty, so that they were also working to support new leaders. And throughout this work, I continued to talk about and invest the classroom as a critical site for instructional leadership. Investing in the classroom as a site of institutional change meant recognizing that widespread pedagogical change is institutional change, and supporting time for faculty to work together on teaching or curriculum is facilitating change.

Community of practice provided an important structure to support change and leadership development among English faculty at Cloudline College. A faculty member who was reluctant to refer to himself as a leader, participated in statewide acceleration training, and eventually began facilitating professional development across the state. His leadership was recognized by his colleagues, and he facilitated communities of practice at the college. The structure of the community of practice scaffolded his development as a leader, and it provided a means for other faculty to take on increased responsibility as well.

My leadership as dean focused on significant outcomes, such as providing more and equitable access to college level courses and achieving success along with access. I 
believed that providing that focus, time for faculty to work together, and support in terms of data, faculty-led professional development, reassignment for leadership, and compensation for PT faculty would result in the transformation that faculty desired and students deserved. Finally, because I value faculty leaders and view the classroom as a pivotal place of leadership, I was able to support faculty as they became crucial leadership partners in initiating change and fulfilling the promise of community colleges that serve all students effectively.

\section{Reflections on Equity}

For more than twenty years, the California Community College system has had evidence that standardized tests used for placement into remedial education systematically obstructed equitable access to college-level courses. The impact of inequitable access to college-level coursework inevitably impacts completion of degrees and certificates of African-American, Latinx, Filipin@, mixed race, Pacific Islander, Native American, and Alaska Native students. Ultimately, impeded access to degrees restricts students' potential for wages and careers, and families and whole communities are impacted.

A paradigm shift is necessary for equity gaps to be closed. Efforts to address equity gaps which rely on perfecting the current system will yield improvements of only one and two percent. Perfecting the current system serves to maintain it rather than challenge it. The current system of developmental English will never close gaps because 
it is underpinned by beliefs that groups of students inherently have deficits. The belief that students had deficits that standardized tests could detect and that remediation would remedy was part of the process of segregating students in the community college system. These beliefs constitute systematic racism and cannot result in equitable outcomes. It is only by confronting and dismantling the system's historical racism that we can achieve equity.

The work that faculty and I conducted at Cloudline College was focused and possible because the college's work was informed by an institutional commitment to educational equity. The president's leadership in developing a comprehensive diversity framework resulted in an analysis of every aspect of the institution through an equity lens. One outcome of this work was that faculty, staff, and administrators worked together with a clear focus on changing the institution in order to achieve equity. The college engaged in the hard work of building an understanding of equity, evaluating the institution through an equity lens, and committing to redesign everything necessary united the college. Doing so focused our work, built our capacity for equity-minded work, and provided a foundation for the work of acceleration.

The paradigm shift we need. Cloudline College's work in developing a comprehensive diversity framework demonstrates that the paradigm shift necessary to close equity gaps shifts the burden from students to colleges. In the traditional paradigm, institutions of higher education protect college standards and limits access to college 
placing the burden on the student to prove they deserve access to higher education. Rather than challenging students to prove their readiness for college, the new paradigm shifts the responsibility to colleges. The new paradigm requires that colleges work with high school graduates at the college level to support their successful entry into and completion of college-level coursework. This shift assumes that students bring assets and strengths. The evidence provided by Cloudline College's implementation of the corequisite model is that students are college ready when colleges engage them appropriately.

Colleges have work to do in order to achieve a paradigm shift. Colleges need to address their misperception of their students' needs by removing deficit-based pedagogies, practices, and policies which have erected barriers for students rather than removing them. In some states, mandates and initiatives have built momentum for the paradigm shift. In California, AB 705 facilitates this paradigm shift by requiring new practices and policies related to placement and developmental pedagogy. The remainder of this chapter addresses recommendations for the implementation of $\mathrm{AB} 705$ and the corequisite model in college-level English.

\section{Recommendations}

The findings of this research have implications for all California community colleges as they prepare for the implementation of $A B$ 705. Asera (2018) writes that "this legislation means that all California community colleges will change - not just those 
colleges that have voluntarily redesigned their courses_-and that the long sequences of courses below transfer will be dismantled" (p. 1). High levels of accountability at every college are necessary for AB 705 to be fulfill its intended goal.

Dismantling developmental sequences. As a first step, developmental sequences should be dismantled. There is abundant research (Bailey et al., 2010; Henry \& Stahl, 2017; Hern \& Snell, 2010) that developmental courses do not successful advance students to college-level coursework, and evidence that the developmental pipeline is leaky even when students complete coursework successfully. Despite this, Hope \& Stanskas (2018) provide room for colleges to resist or delay change by allowing colleges to require students "who are highly unlikely to succeed in transfer-level coursework" (p. 3) to enroll in developmental courses. It is quite likely that colleges that have maintained long developmental sequences have done so because they believe that their students are highly unlikely to succeed in transfer-level coursework.

AB 705 provides for these students to have access to college-level courses, and administrators and faculty advocates need to ensure that college-level courses are accessible. Developmental courses should no longer be scheduled, and enough sections of college-level classes need to be scheduled to ensure that students have access to college-level English. College district leadership, CEOs and CIOs have the responsibility to ensure that students have access to college-level coursework. They ensure that deans, 
department chairs, coordinators and faculty have support and access to the resources they need to implement the law.

Instructional time. While students need to be provided equitable access to college-level courses, many will need the support of co-requisites. Co-requisites can be required and play a role in the closing equity gaps. Administrators need to ensure that faculty are not discouraged from requiring that students enroll in a co-requisite.

The impetus for $\mathrm{AB} 705$ was to ensure that students were not delayed by unnecessary requirements. As we implement $\mathrm{AB} 705$, our responsibility is to provide access and success. Administrators and faculty should not be so eager to assign students standalone transfer-level English classes that their likelihood of success in the class is compromised. To effectively implement $\mathrm{AB} 705$, it is crucial to distinguish the long developmental sequences that predated with $\mathrm{AB} 705$ from the brief co-requisite courses and co-curricular support that ensure the success of $\mathrm{AB} 705$. In a memorandum on the implementation of AB 705, Hope \& Stanskas (2018) caution that co-curricular support "should be developed with an eye on maintaining reasonable unit thresholds" (p. 9). Whereas long, developmental sequences required many units and semesters, and barred students from college-level enrollment, co-requisites require as few as one or two units, and accompany enrollment in college-level courses. Research indicates that the additional instructional time offered by the co-requisite is critical to student success and equitable outcomes ( Cho et al., 2010; Coleman, 2014). 
Curriculum redesign. Hope \& Stanskas (2018) clearly state that significant curricular reforms are necessary in order to successfully implement AB 705. This research also confirms that the co-requisite model requires that faculty redesign curriculum. At a minimum, faculty must design the co-requisite supports that students need to ensure successful completion of the first college-level course. However, there is an opportunity for faculty to do more than design a co-requisite course when they are reforming remedial education. Transformative curriculum redesign challenges the philosophical and pedagogical basis of traditional remediation. The paradigm shift from regarding students as bringing deficits that hinder learning to regarding students as possessing assets that support learning mandates a different curriculum and pedagogy. The opportunity for faculty to thoughtfully transition from a deficit model to an asset model can enhance both learning and teaching.

Professional development. Professional development can support and facilitate the transformative changes needed to achieve equity. In their July 2018 memo, Hope \& Stanskas fail to acknowledge the importance of faculty engaging in professional development to implement $\mathrm{AB} 705$. The significant reform that $\mathrm{AB} 705$ mandates is best supported by time, funding, and other resources committed for professional development. College administrators and faculty leaders should consider professional development an essential component of any $\mathrm{AB} 705$ implementation plan. 
A supportive professional development program provides focus, time, space and resources for faculty to learn and work. The California Acceleration Project has led transformative work within the state using community of practice as their model for professional development. As a professional development model, community of practice is non-hierarchal and begins with the premise that all participants are valued contributors and learners. Faculty beliefs and attitudes are unlikely to change or transform when professional development provides a set of correct answers that faculty are expected to passively absorb. When faculty are given the opportunity to help construct learning experiences that will allow them to meet new goals or design and implement new programs, the experience of contributing to the professional development and engaging in co-constructed professional development can effectively facilitate changes in beliefs, attitudes, and practices.

The relationships that develop within effective professional development programming become a means of ensuring that learning is implemented and ongoing. Peers learning together implicitly develop systems of accountability. When faculty members co-develop concepts and learn and change together, they have accomplished learning together. This shared achievement takes them to a new place in their professional understanding and commitment. Some peers within professional development communities develop explicit means of accountability by collaborating in the teaching and learning process. These collaborative relationships, implicit or explicit, 
are a means of extending the effect of professional development and ensuring that professional learning and growth is ongoing.

The potential of $\mathrm{AB} 705$ specifically and developmental reform generally is that transformative change will occur. Shields (2010) asserts that transformative changes looks beyond organizational change to effect justice and equity. For developmental reform to result in equity and justice, we have the opportunity to change more than the structure of developmental education.

Transformative developmental reform requires a change in the foundational beliefs held about students who the system designates as developmental (Solorzano \& Bernal, 2001). The traditional remedial system perceives of groups of students as deficient, coming from communities and schools that are also judged as deficient (Gutierrez, Morales \& Martinez, 2009). These beliefs are undergirded by a racism that sets low expectations for whole groups of students. Even when individuals working within the system do not hold these negative beliefs about students, their schools, or their communities, they may act in compliance with the traditional remedial system. In order to address the philosophical remnants of the system that implemented and maintained traditional remedial education, changes must be made to professional development, curriculum, and pedagogy. Professional development, curriculum, and pedagogy are crucial components that reflect core systemic beliefs about students, faculty, and the nature of teaching and learning. 


\section{Conclusion}

The text of AB 705 acknowledges that for decades, California legislators and community college officials have been aware that colleges' use of assessment tests for placement bars some college-ready students from college-level courses. The bill cites multiple failures of California's community colleges, codes, and regulations to protect students' rights and provide fair access to college. The Mexican American Legal Defense and Education Fund suit, which attempted to require colleges to provide equitable access to college-level courses, did not result in changes to placement practices. Title 5 regulations requiring the use of multiple measures of assessment did not change college's practices in placement testing. Title 5 did not prevent colleges from blocking students from college-level coursework. If we allow it to, AB 705 could fail our students in the same way. Without strong leaders in the state who are willing to hold themselves and their peers accountable, our students will again suffer the injustices of an unfair system. Our system needs bold, equity-minded faculty and administrators to lead the way in implementing this reform. Alongside them, we need leaders who are willing to ensure that developmental courses are removed from our curriculum to ensure that our students receive the education that is rightfully theirs.

Hope \& Stanskas (2018) conclude their memo with a focus on the promise of AB 705. They remind us that with this reform, we have the opportunity to address inequity within our system. Paradigm shifts in education may be initiated by policy changes, but 
policy change alone is insufficient to create equity and social justice. In the reform of remedial English, AB 705 effectively changes structure and policy. Faculty leaders working with the support of administrators are responsible for the philosophy, pedagogy, and practices that will ultimately produce equitable outcomes for California community college students. AB 705 promises hope for our future, if we are emboldened to enact. 


\section{References}

Asera, R. (2018). A brief history of California's changing approach: Basic skills and beyond. Center for the Analysis of Postsecondary Readiness.

Attewell, P., Lavin, D., Domina, T., \& Levey, T. (2006). New Evidence on College Remediation. The Journal of Higher Education, 77(5), 886-924.

https://doi.org/10.1353/jhe.2006.0037

Bailey, T. (2009). Challenge and opportunity: Rethinking the role and function of developmental education in community college. New Directions for Community Colleges, 2009(145), 11-30. https://doi.org/10.1002/cc.352

Bailey, T., Jaggars, S., \& Jenkins, D. (2015). Redesigning America's Community Colleges: A clearer path to student success. Cambridge, MA: Harvard University Press.

Bailey, T., Jeong, D., \& Cho, S. (2010). Referral, enrollment, and completion in developmental education sequences in community colleges. Economics of Education Review, 29(2), 255-270.

https://doi.org/10.1016/j.econedurev.2009.09.002

Booth, K., Cooper, D., Karahdjeff, K., Large, M., Pellegrin, N., Purcell, R., ... Willett, T. (2013). Using student voices to redefine success: What community college students say institutions, instructors, and others can do to help them succeed.

Charmaz, K. (2006). Constructing grounded theory. Thousand Oaks, CA: Sage. 
Cho, S., Kopko, E., Jenkins, D., \& Jaggars, S. (2012). New Evidence of Success for Community College Remedial English Students: Tracking the Outcomes of Students in the Accelerated Learning Program (ALP). CCRC Working Paper No. 53. Community College Research Center, Columbia University. Retrieved from http://eric.ed.gov/?id=ED538995

Coleman, D. (2014). Replicatting the accelerated learning program: Preliminary but promising findings. Charlotte, NC: Center for Applied Research.

Cooper, D., Fong, K., Karandjeff, K., Kretz, A., Nguyen, A., Purnell-Mack, R., \& Schiorring, E. (2017, November). Through-the-Gate-Phase-I-TechnicalReport.pdf.

Creswell, J., \& Plano, C. (2011). Designing and conducting mixed methods research. Los Angeles, CA: Sage Publications.

Denley, T., \& Knox, P. (2016). Building Student Success with Mindset Know-How. Tennessee Board of Regents.

Dweck, C. (2008). Mindset :the new psychology of success. New York: Ballantine Books.

Edgecombe, N., Cormier, M., Bickerstaff, S., \& Barragan, M. (2013). Strengthening Developmental Education Reforms: Evidence on Implementation Efforts from the Scaling Innovation Project. CCRC Working Paper No. 61. Community College Research Center, Teachers College. Columbia University. 
Edgecombe, N., Jaggars, S., Xu, D., \& Barragan, M. (2014). Accelerating the integrated instruction of developmental reading and writing at Chabot College. New York, NY: Community College Research Center, Teachers College, Columbia University. Retrieved from http://core.ac.uk/download/pdf/27299249.pdf

Goudas, A. (2017). Corequisites: The good, the bad, and the ugly. Oklahoma City, OK. Goudas, A., \& Boylan, H. (2012). Addressing flawed research in developmental education. Journal of Developmental Education, 36(1), 2.

Grubb, N., \& Gabriner, R. (2012). Basic Skills Education in Community College: Inside and Outside of Classrooms. Routledge.

Gutierrez, K., Morales, P., \& Martinez, D. (2009). Re-mediating literacy: Culture, difference and learning for students from non-dominant communities. Review of Research in Education, 33, 212-247.

Henry, L., \& Stahl, N. (2017). Dismantling the developmental education pipeline: Potent pedagogies and promising practices that address the college readiness gap. Journal of Adolescent and Adult Literacy, 60(6), 611-616.

Hern, K. (2012). Acceleration across California: Shorter pathways in developmental English and math. Change: The Magazine of Higher Learning, 44(3), 60-68.

Hern, K., \& Snell, M. (2010). Exponential attrition and the promise of acceleration in developmental English and math. Research and Planning Group of the California Community Colleges, Www. Rpgroup. Org/Rpsearch/Results/Taxonomy\% $3 A 17$. 
Hern, K., \& Snell, M. (2014). The California Acceleration Project: Reforming Developmental Education to Increase Student Completion of College-Level Math and English: The California Acceleration Project. New Directions for Community Colleges, 2014(167), 27-39. https://doi.org/10.1002/cc.20108

Hildreth, P., Kimble, C., \& Wright, P. (2000). Communities of practice in the distributed international environment. Journal of Knowledge Management, 4(1), 27-38.

Hodara, M., \& Jaggars, S. (2014). An examination of the impact of accelerating community college students' progression through developmental education. The Journal of Higher Education, 85(2), 246-276.

Hope, L., \& Stanskas, J. (2018, July 11). Memorandum, RE: Assembly bill (AB) 705 implementation.

Jenkins, D., Speroni, C., Belfield, C., Jaggars, S., \& Edgecombe, N. (2010). A Model for Accelerating Academic Success of Community College Remedial English Students: Is the Accelerated Learning Program (ALP) Effective and Affordable? CCRC Working Paper No. 21. Community College Research Center, Columbia University. Retrieved from http://eric.ed.gov/?id=ED512398

Jones, M. (2018, July). Challenging academia's oppresive language: A call to action. Presented at the San Francisco State University Educational Leadership and Communication, San Francisco. 
Kabat-Zinn, J. (1994). Wherever you go, there you are: Mindfulness meditation in everyday life. New York: Hyperion.

Karp, M., \& Bork, R. (2014). They never told me what to expect, so I didn't know what to do": Defining and clarifying the role of a community college student. Teachers College Record. Retrieved from https://scholar.google.com/scholar?cluster=11725618528511865089\&hl=en\&as $\mathrm{sdt}=0,5 \&$ sciodt $=0,5$

Kezar, A., \& Gehrke, S. (2017). The Roles of STEM Faculty Communities of Practice in Institutional and Departmental Reform in Higher Education Sean Gehrke, Adrianna Kezar, First Published May 19, 2017. American Educational Research Journal.

Landsberger, H. (1958). Hawthorne revisited. Management and the worker: its critics, and developments in human relations in industry. Ithaca, NY: Cornell University.

Lave, J., \& Wenger, E. (1991). Situated learning: Legitimate peripheral participation. Cambridge: Cambridge University Press.

Levshina, N. (2015). How to do linguistics with R: Data exploration and statistical analysis. John Benjamins.

McDermott, R., \& Archibald, D. (2010). Harnessing your staff's informal networks. Harvard Business Review, 88(3), 82-89. 
Novak, G., Patterson, E., Gavrin, A., \& Christian, W. (1999). Just-in-Time Teaching: Blending active Learning and Web Technology. Saddle River, NJ: Prentice Hall.

Paris, D. (2012). Culturally sustaining pedagogy: A needed change in stance, terminology, and practice. Educational Researcher, 2012(41), 93-97.

Park, T., Woods, C., Richard, K., Tandberg, D., Hu, S., \& Jones, T. (2015). When Developmental Education is Optional, What Will Students Do? A Preliminary Analysis of Survey Data on Student Course Enrollment Decisions in an Environment of Increased Choice. Innovative Higher Education, 41(3), 221-236. https://doi.org/10.1007/s10755-015-9343-6

Perin, D. (2002). The Location of Developmental Education in Community Colleges: A Discussion of the Merits of Mainstreaming vs. Centralization. Community College Review, 30(1), 27-44. https://doi.org/10.1177/009155210203000102

Perry, M., Bahr, P., Rosin, M., \& Woodward, K. (2010). Course-Taking Patterns, Policies, and Practices in Developmental Education in the California Community Colleges. A Report to the California Community Colleges Chancellor's Office. EdSource.

Rodriguez, O., Mejia, M., \& Johnson, H. (2016). Determining college readiness in Calffornia's community colleges: A survey of assessment and placement policies.

Saldaña, J. (2013). The coding manual for qualitative researchers. Los Angeles, CA: Sage Publications. 
Scott-Clayton, J., \& Rodriguez, O. (2012). Development, discouragement, or diversion? New evidence on the effects of college remediation. National Bureau of Economic Research.

Shields, C. (2010). Transformative Leadership: Working for Equity in Diverse Contexts. Educational Administration Quarterly, 46(4), 558-589. https://doi.org/10.1177/0013161X10375609

Solorzano, D., \& Bernal, D. (2001). Examining transformational resistance through a critical race and LatCrit theory framework Chicana and Chicano students in an urban context. Urban Education, 36(3), 308-342.

Wenger, E. (1998). Communities of practice: Learning, meaning, and identity. Cambridge: Cambridge University Press.

Wenger, E., McDermott, R., \& Snyder, W. (2002). Cultivating communities of practice: A guide to managing knowledge. Cambridge, MA: Harvard Business School Press.

Wiggins, G., McTighe, J., Frost, F., Kiernan, L., \& Association for Supervision and Curriculum Development. (1998). Understanding by design. Alexandria. Va: Association for Supervision and Curriculum Development. Alexandria, VA: Association for Supervision and Curriculum Development.

Woods, C., Park, T., Hu, S., \& Bertrand Jones, T. (2017). Reading, writing, and English course pathways when developmental education is optional: Course enrollment 
and success for underprepared first-time-in-college students. Community College Journal of Research and Practice, 1-21.

https://doi.org/10.1080/10668926.2017.1391144 


\section{Appendix A}

\section{Interview with Katie Hern, June 11, 2018}

MG: Why community of practice?

KH: When CAP started in late 2010-early 2011, we were partnering with 3CSN and conducting institutes that took a full school year. The institutes ran in summer, fall, winter and when a college committed, they participated in all three institutes. We wanted people to feel supported in the changes that they were making. The financial support was provided by $3 \mathrm{CSN}$ and a grant from BSI. $3 \mathrm{CSN}$ was covering costs like travel, lodging, and food. The initial group was small, about 57 people. With a small group we were using a professional development model of sustained, peer-to-peer, learning. At the time, $3 \mathrm{CSN}$ was working with a theory of change that involved peer-to-peer learning.

KH: I suggested calling it a fellowship, but people thought it was . . sounded Christian-MG: You meant like a graduate fellowship.

KH: Yeah, like a graduate fellowship. And Jan Connal, who was a regional coordinator with $3 \mathrm{CSN}$ at the time, was studying community of practice or aware of community of 
practice. I may have pulled community of practice out of the ether or it may have been suggested by Jan.

MG: What was useful about community of practice?

$\mathrm{KH}$ : Working through problems of practice with other practitioners - this is the vision for it. Participants were there to grapple with the problems. Community of practice has a flattened hierarchy. We didn't have authority; we were just facilitators of a process. People were there with the intention of learning to do something different. At the time it seemed so radical to make the structural change. People were changing from three levels below transfer to one, or two levels below to one. We were there to say 'Here's what I use in my class.' They were hungry to see the approaches.

MG: It seems like that's still very much of the culture on the Facebook page.

KH: The CAP Facebook page captures the spirit of the work, the sharing. The Facebook group manifested the peer to peer work/network. It also provides relief for the folks who were coaching or facilitating because there are so many people who can respond, whereas the coaching was one-on-one. People can answer technical issues with multiple measures that I don't have the answers to. 
MG: One of the things that we've become aware of is that community of practice is an asset-based model. There is professional development that is deficit-based. We've seen that a lot of the things that faculty learn are good for students are good for faculty too. The Six Factors are just good for humans.

$\mathrm{KH}$ : Faculty would often observe that we modeled the environments we were trying to create in classrooms. Their comments made me more conscious of and more intentional about what we were doing. (KH clarifies that asset-based doesn't mean that anything goes in CAP.) There are shared bottom lines, we use empirical evidence to support the work. CAP defines the principles, the principles came first and people had to be willing to start with those principles.

$\mathrm{KH}$ : In the beginning, we had few resources and we had to make sure that the colleges we were working with were on board with our principles and were ready to implement redesigned classes. For example, participants had to be interested in shortening students' path to and through transfer-level courses, in math they had to be doing an accelerated statistics pathway in the beginning (we have now broadened to include B-STEM math), could not just be a compressed model of the same content as the traditional remedial classes (e.g., with all the same algebra intact) - had to be backward designed from the college-level class, had to employ just-in-time remediation rather than front-loaded decontextualized skills. The principles were framed by the CAP founders. We were 
really aware of what we were supporting people to do, and we were not interested in things that didn't align. We rejected the applications that didn't align. We needed colleges to do work that aligned, that would use the resources well, and advance the cause. The objectives and principles were broadly defined enough for colleges to contribute/design, but they had to commit to running at least two sections of accelerated models that aligned with CAP design principles. Those principles were the thing that unites us, the framework, and the people who stepped forward were compelled by the framework and the agreements. 


\section{Appendix B}

\section{Explanation of linguistic choice}

Throughout my dissertation, I have rejected using language that names groups of students by their relationship to the social system and/or to the educational system. My colleague, Marilyn Jones, has heightened my attention to the ways that language can reinscribe the very social conditions that it intends to condemn. Jones (2018) (Jones, M., 2018)challenges academia to develop a consciousness regarding oppressive language. (Paris, D., 2012) also provides a discussion of this linguistic phenomenon. In this dissertation, I refer to student populations by terms such as African American, Latinx, and Filipin@. When possible, I have elected to use terms that have developed within the population that I am referring to. 